\title{
Valorisation of Bagasse Cane by-Product: Effect of Cellulosic Fibers and Coupling Agent on Thermal, Mechanical and Rheological Behaviours of Reinforced Polypropylene
}

Abdelghani BOUSSETTA

Sultan Moulay Slimane University Polydisciplinary Faculty of Beni Mellal

Hassan CHARII

Sultan moulay sliman university

Anass AIT BENHAMOU

Cadi Ayyad University

Francisco J. BARBA

Universitat de Valencia - Campus Blasco Ibanez

Nabil GRIMI

Sorbonne Université, Université de Technologie de Compiègne

Mario J. SIMIRGIOTIS

Universidad Austral de Chile

Amine MOUBARIK ( $\square$ a.moubarik@usms.ma )

Sultan Moulay Slimane University

\section{Research Article}

Keywords: By-Product, Bagasse cane, Cellulose microfibers, Composites, Polymer, Mechanical properties, Rheological behaviour.

Posted Date: November 2nd, 2021

DOI: https://doi.org/10.21203/rs.3.rs-963341/v1

License: () (1) This work is licensed under a Creative Commons Attribution 4.0 International License. Read Full License 


\section{Abstract}

Recently more attentions are growing every day towards the valorisation of industrial by-product especially those generated through agriculture and food industries, as the demands of bio-based resources for the necessary transition from fossil hydrocarbon sources to natural based products are increasing. This paper focuses on the potential effect of chemical treatments and modification as well as fibers loading on the thermal, mechanical, and rheological behaviour of reinforced Polypropylene (PP). During this work, fibers were prepared using alkali and bleaching treatments and then characterized using different analysis such SEM, X-ray, FT-IR and TGA/DTG. The composite materials were elaborated using twin-screw extrusion followed by injection molding by mixing PP with 5 to $10 \mathrm{Wt}$.\% of raw bagasse cane (RBC), alkali bagasse cane (ABC) and bleached cellulose microfibers (BCM) as well as cellulose microfibers with Styrene-(ethylene-butene)-styrene three-block copolymer grafted with maleic anhydride (SEBS-g-MA) as coupling agent. The result achieved from this study shows that the use of different type of fibers led to significant decrease in thermal degradation of PP. The mechanical results show a significant improvement in Yung's modulus, tensile strength and hardness of the reinforced PP compared to neat PP. However, a remarkable decrease was obtained in elongation at break and toughness for all reinforced composites compared to neat PP. Besides, higher and low torsion modulus was obtained for PP reinforced with BCM and SEBS-g-MA-BCM, respectively.

Statement of Novelty: This study aims to valorise bagasse sugar cane by-product as a lignocellulosic source for the isolation of cellulose fibers. Innovative composite materials were prepared based on polypropylene.

\section{Introduction}

In the sphere of composite materials, plastics and ceramics are the most used matrices in different field of application especially in the aerospace sector[1], automotive industry [2], 3D printing[3], bio-medical industry [4] and daily use. The main common and applied modifications is reinforcing these materials using different fibers such as glass, carbon and aramid fibers. Developing new composite materials may be started by the desire to obtain materials that can support conditions in their range of its applications such as temperature, strength, etc. Regarding the development of a new composites based on thermoplastic matrix, several works are conducted toward the modifications of these conventional materials by adding directly fibers inside matrices[5] or by chemical modifications[6, 7] aiming to change their physical behaviours that cannot be provided by neat polymer.

Nowadays much academic research and industrial projects work intensively toward implementing the use of natural fibers as a reinforcement for composites[8-11]. Biomass is considered as an environmentally friendly source that has attracted significant attention of several countries to develop new methods and approaches to benefit from it, since it is the main renewable and sustainable wealth. In addition, lignocellulosic biomass such as forest resources, agricultural, animal and municipal wastes are considered as alternative sources that can provide the possibility to prepare natural fibers that can imply or play the same roles as conventional fibers $[12,13]$ The use of natural fibers as a reinforcement for polymer matrix has evolved dramatically because they have the potential to replace man-made fibers in composite materials[14]. Moreover, natural fibers have the advantages of being less expensive, low density, recyclable, biodegradable and more viable [15, 16].

Recently, the use of fibers in the development of bio-composites attracts more and more attention of several researchers, which can provide access to high added value applications[17-19]. The development of reinforced thermoplastic polymers with cellulose fibers has brought several challenges such low compatibility between the hydrophilic cellulose and hydrophobic polymers[20]. These challenges led to weak interfacial adhesion, non-uniform dispersion, and high agglomeration. In fact, these drawbacks are limiting its applications. The chemical modifications are one of the efficient methods that have been proposed recently to overcome these limitations. Generally, alkaline, bleaching treatment and surface functionalization/grafting have been proposed by several studies.[21-23]. However, the chemical treatment is an effective method for surface fibre modification. During treatment all no-cellulosic compounds such as lignin, pectin and wax were removed. Cleaning surface fibers allows possibility to add functional groups leading to low surface polarity and giving as result good adhesion particularly at the interface of fibers and matrix as well as excellent fibers dispersion. On the other hand, to improve the fibre's-matrix interfacial 
bonding, coupling agent such as maleic anhydride grafted styrene-(ethylene-butene)-styrene (SEBS) can be used during melt blending due to its compatible structure particularly with polypropylene (PP) or high-density polyethylene (HDPE) [20, 24].

Sugar is one of the most consumed substrates in the world and considered as a requisite food for humanity. The demand of refined sugar in the world is high, and the sugar industry aims to produce a significant quantity to meet the population needs [25]. Bagasse cane is the preferred source as raw material to produce refined sugar. During the process of production, an important quantity of by-product is generated in the form of lignocellulosic biomass generated as waste from bagasse sugar factories. Sugar bagasse by-product mainly made up of $45-50 \%$ water, $40-45 \%$ fibers, and $2-5 \%$ dissolved sugars [26]. Bagasse cane by-product is deemed as a fibrous material which is composed mainly of $40-50 \%$ cellulose, $25-35 \%$ hemicellulose and 20 $30 \%$ lignin [27]. Due to its composition, much research targets the valorisation of this lignocellulosic fortune and looks for an economic approach for the management of these industrial wastes. In this respect, bagasse cane is used for ethanol production $[28,29]$, for removal of dye from aqueous solution [30], elaboration of nanocomposite film [31] important source for the isolation of lignin for wood adhesives [32] and composite materials[33, 34].

This work attempts to comparatively gauge the effect of alkali and bleaching treatments for bagasse fibers on the mechanical and rheological behaviours of the reinforced PP. At the outset all fibers were characterized using different complementary analysis such as scanning electron microscope (SEM), X-ray diffraction (XRD) and Fourier Transformed Infrared (FTIR) and thermal analysis (TGA/DTG) aiming to investigate the main difference between the prepared fibers as well as prove the effectiveness of chemical treatment. The obtained fibers were mixed with PP in a thermokinetic mixer. Fibre's composition used was starting from 2.5 to $10 \mathrm{Wt}$. \% using twin-screw extrusion followed by injection molding. However, the use of coupling agents for composite based on bleached cellulose microfibers and PP which can be beneficial to improve interfacial adhesion. In fact, the thermal, mechanical and rheological behaviours of PP/ fibers composite with chemically treated and modified fibers will be compared to the results obtained from untreated fibers composite as well as neat polymer at different loading.

\section{Materials And Methods}

\subsection{Materials}

Raw bagasse cane by-product (RBC) collected from the various sugarcane juice shop in Beni Mellal city (Morocco) located approximatively $225 \mathrm{~km}$ far from Casablanca city and are leads to dry for 2 to 3 days. RBC were sun-dried, cut into 2-4 cm long sticks, ground and stored before use. The moisture content at equilibrium was up to 6-8 \%. Sodium hydroxide $(\mathrm{NaOH})$, sodium chlorite $\left(\mathrm{NaClO}_{2}\right)$, acetic acid solution $\left(\mathrm{CH}_{3} \mathrm{COOH}\right)$, sodium hypochlorite solution $(\mathrm{NaClO})$, other chemicals were acquired from

Sigma Aldrich. The thermoplastic PP was supplied by ExxonMobil chemical was used with a density of $0.9 \mathrm{~g} \cdot \mathrm{cm}^{-3}$ and melting temperature of $165^{\circ} \mathrm{C}$. The compatibilizer agent is styrene-(ethylene-butene)-styrene triblock copolymer grafted with maleic anhydride (SEBS-g-MA), which was supplied by Shell (Kraton FG- 1901X) containing 1.4-2\% wt. MA.

\subsection{Fibre's preparation}

Figure 1. shows the extraction of $A B C$ and $B C M$ from RBC. The extraction was performed according to the process used in our previous works $[5,14,20,34]$. Firstly, RBC fibers were subjected to treatment using distilled water at $70^{\circ} \mathrm{C}$ during $2 \mathrm{~h}$ under mechanical stirring, with a 1:10 solid-to-liquid ratio aiming to remove hemicellulose and other water-soluble materials from raw material. Furthermore, the pre-treated fibers were filtered to remove the water-soluble fractions. Secondly, the resulted residue was alkali treated using aqueous sodium hydroxide solution during 90 minutes at $98^{\circ} \mathrm{C}$ under mechanical stirring to break the linkage between lignin and cellulose fibers resulting in alkali bagasse cane (ABC). The alkali-treated fibers were subjected to an effective filtration in order to remove black liquor from cellulose fibers. In fact, alkali treatment removes a certain amount of lignin, wax and oils that covers the external surface of fibers cell wall. For this purpose, the alkali-treated fibers were bleached at $80^{\circ} \mathrm{C}$ for $2 \mathrm{~h}$, using a bleaching solution which contains acetate buffer $(27 \mathrm{~g} \mathrm{NaOH}$ and $75 \mathrm{~mL}$ glacial acetic acid, diluted to $1 \mathrm{~L}$ of distilled water) and (1.7 wt\% $\mathrm{NaClO}_{2}$ in water). During bleaching treatment, the ratio of the fibers to liquor was fixed at $1 / 20$ $(\mathrm{g} / \mathrm{mL})$. To ensure further removal of the amorphous components, the bleaching process was repeated for three times. The asobtained cellulose microfibers were washed using distilled water and air-dried resulting in bleached cellulose microfibers (BCM). 


\subsection{Composites processing}

During this work composites were prepared by mixing neat PP with untreated, alkali, bleached fibers at different loading with the aiming to investigate the effect of chemical treatments and coupling agent on the thermal, mechanical, and rheological properties of the elaborated composites compared to neat polymer. Various fibers loadings were used in this study ranging from 2.5, 5 to 10 wt.\% which were blended with PP pellet using a Leistritz ZSE-18 Twin Screw Extruder (Leistritz Extrusions technik $\mathrm{GmbH}$, Germany). The mixing process was carried out using a speed of $125 \mathrm{rpm}$ for the main screws and a 40-rpm side-feeder screw speed for particles feeding. However, the temperature profile of the extruder barrel's seven zones was set from hopper to die at $170{ }^{\circ} \mathrm{C}, 170{ }^{\circ} \mathrm{C}, 175^{\circ} \mathrm{C}, 180^{\circ} \mathrm{C}, 180^{\circ} \mathrm{C}, 175^{\circ} \mathrm{C}, 170{ }^{\circ} \mathrm{C}$ and $170{ }^{\circ} \mathrm{C}$, respectively. Afterwards, the strands coming out from the extruder were cooled in a water bath and pelletized into pieces of 2-3 mm length using a pelletizer Fritsch pulverisette 19 Germany (Thermo Fisher, UK).). To perform tensile and torsion tests, specimens were prepared using injection molding machine with a 40 tons platen force. The temperature of the injection process was fixed at $180^{\circ} \mathrm{C}$ in the press barrel while the in nozzle was set at $170{ }^{\circ} \mathrm{C}$ and mold was maintained at $45^{\circ} \mathrm{C}$ [35] (Fig. 2).

\subsection{Fiber's characterization}

\section{Scanning electron microscopy (SEM)}

The morphological features of different fibers obtained through chemical treatments of bagasse cane by-product were evaluated using a TESCAN VEGA 3 microscope acceleration voltage was $10 \mathrm{KV}$, working distance $10 \mathrm{~mm}$. The surfaces of fibers were vacuum coated with carbon using an ion sputtering apparatus with a Scan coat Six sputtering machine from Edwards.

\section{Fourier transform infrared spectroscopy (FTIR)}

The chemical composition was investigate using Bruker-Vortex 70 FT-IR spectrometer in order to identify characteristic bands of each fibre as well as investigate the effectiveness of the chemical process used to remove all no-cellulosic compounds. Subsequently, fibers were ground and mixed with dried $\mathrm{KBr}$ (sample/ $\mathrm{KBr}$ ratio, $1 / 100$ ) to prepare pastilles. The analysis was carried out covering the frequency ranging from $400-4000 \mathrm{~cm}^{-1}$ with a resolution of $4 \mathrm{~cm}^{-1}$ and accumulation of 32 scans.

The elaborated composites particularly the compatibilized one PP/SEBS-g-MA-BBC) was investigated to prove the role of coupling argent in fibers matrix adhesion. FT-IR analyses were performed out using a JASCO FT/IR-4600 spectrometer equipped with ATR accessory. The FTIR spectra were recorded in $4000-600 \mathrm{~cm}^{-1}$ range with a resolution of $4 \mathrm{~cm}^{-1}$ and an accumulation of 16 scans.

\section{X-ray diffraction (XRD)}

The X-ray diffraction of the prepared fibers were performed using a RIGAKU diffractometer with CuKa radiation at a wavelength of $1,54060 \AA$. The diffraction profiles were obtained at diffraction angles between 5 and $40^{\circ}$ ( $2 \theta$ angle range) at a speed of $5^{\circ}$ per min at room temperature with a scan rate of $0.018 \circ \mathrm{s}^{-1}$. X-Ray diffraction was used in this study aiming to investigate and compare the crystallinity index of each the fibre. The crystallinity index (Crl) of the prepared fibers was evaluated using Segal method[36] as shown in Eq. (1)

$$
C r I=\frac{I_{200}-I_{a m}}{I_{200}} \times 100
$$

were

$I_{200}$ is the intensity of the 200-lattice plane at around $2 \theta=22.8^{\circ}$, and $I_{a m}$ is the intensity

from the amorphous phase at approximately $2 \theta=18.6^{\circ}$.

Thermal characterization (TGA/TDA) 
The thermal stability of fibers were carried out using a thermogravimetric analyser (TGA) using LABSYS evo TGA 1600 from SETARAM Instruments. Analysis was carried out under atmospheric pressure conditions, fibers of 2-20 mg was heated up from 30 to $700^{\circ} \mathrm{C}$ at a heating rate of $10^{\circ} \mathrm{C} / \mathrm{min}$. The rate of weight change was evaluated using derivative thermogravimetric analysis DTG which is determined as the first derivative of the TGA analysis. Thermal analysis measurements of all composite were carried out under atmospheric conditions using SETARAM LABSYS evo (TGA/DSC 1600) in order to get information about thermal degradation of the reinforced PP.

\subsubsection{Tensile properties}

Tensile tests of the prepared composites were evaluated using universal testing machine INSTRON 8821S (Instron, USA) at crosshead speed of $3 \mathrm{~mm} / \mathrm{min}$ using a $5 \mathrm{kN}$ load cell at ambient temperature and relative humidity between $30 \%$ and $40 \%$ according to ISO 527-01, 1993 [37]. Tensile properties such as Young's modulus, tensile strength, elongation at break and toughness of the elaborated composites were determined from the stress-strain curves. During this test three samples were tested, the averages and standard deviation were used as representative values.

\subsubsection{Hardness properties}

Hardness tests were used in this study aiming to investigate the ability of the elaborated composites to resist penetration under load and a fixed speed. This test were performed according to ASTM D2240 [38]. The hardness test was carried out using a hardness tester Hildebrand (fully automatic system for durometer hardness testing) and expressed as Shore D hardness at $26^{\circ} \mathrm{C}$ and the humidity about $41 \% \mathrm{RH}$. Tests were performed on the surface of the prepared samples $(24 \mathrm{~mm} \times 24 \mathrm{~mm} \times 2 \mathrm{~mm})$ under a cross speed set at $3 \mathrm{~mm} / \mathrm{min}$. The values reported are an average from three measurements.

\subsubsection{Torsion properties}

Torsion tests were carried out using ARES-LS (TA instruments, UK) rheometer operating in rectangular torsion mode. The samples were prepared according to the following dimensions $5.5 \mathrm{~mm}$ width, $56.5 \mathrm{~mm}$ length, and $2 \mathrm{~mm}$ thick samples. The torsion modulus $\left(\mathrm{G}^{*}\right)$ and the loss factor $\tan (\delta)$ were obtained using oscillatory tests. This test was performed at $25^{\circ} \mathrm{C}$ under different frequencies starting from $0.1 \mathrm{~Hz}$ to $40 \mathrm{~Hz}$, where $0.1 \mathrm{~Hz}$ is a near quasi static frequency and $40 \mathrm{~Hz}$ is an optimized frequency at a deformation of 0.002 . The torsion modulus $\left(\mathrm{G}^{*}\right)$ and the damping factor $\tan (\delta)$ were calculated using the following equation:

$$
\begin{gathered}
G^{*}=\sqrt{\left(G^{\prime}\right)^{2}+\left(G^{\prime}\right)^{2}} \\
\tan (\delta)=\frac{G^{*}}{G^{\prime}}
\end{gathered}
$$

Where $\mathrm{G}^{\prime}$ and $\mathrm{G}^{\prime \prime}$ are the storage and loss moduli, respectively.

\subsection{Statistical analysis}

All tests were performed on at least three samples, the means and standard deviations of data were calculated. The data were analysed statistically to verify the significance of the variables studied using Origin Lab (version 2016, Massachusetts, USA). The collected data were analysed using one-way analysis of variance (ANOVA) and the means were separated using post-hoc Fisher LSD as a means comparison method to evaluate the significant difference test. For each analysis, a significance level of $5 \%$ was assumed.

\section{Results And Discussion}

\subsection{Bagasse fibers characterization}


The morphology of raw bagasse cane (RBC), alkali-treated bagasse cane $(A B C)$ and bleached cellulose microfibers (BCM) were analysed using SEM observation as illustrate Fig. 3. The images below show a significant change from raw material to bleached cellulose microfibers. Raw bagasse cane Fig. 3. (a) shows strongly bonded fibers with a rough compact surface, this roughness indicates that cellulose fibers are submerged in an open matrix of hemicellulose, lignin and other non-cellulosic compound such as waxes and pectin, which are scattered over the surface. In addition, Fig. 3. (b) shows the potential of alkaline treatment to remove partially all non-cellulosic compounds from raw material, resulting in partial defibrillation of fibers. The SEM micrograph obtained for BCM Fig. 3. (c) shows that the bleaching treatment led to total defibrillation giving as a result individual microfiber, the BCM fibers appear separated into individual grouped structures of micro-dimensions. These results are strongly consistent with previous works which isolated cellulose microfibers from different lignocellulosic fibers using the same process (alkali and bleaching treatment) $[22,23]$.

The X-ray diffraction of the isolated fibers is shown in Fig.4. The XRD patterns of samples illustrates the presence of three diffraction peaks at $2 \theta=14.93^{\circ}, 16.9^{\circ}, 22.4^{\circ}$ and $34.8^{\circ}$ corresponding to the (110), (110), (200) and (004) crystallographic planes, respectively. These are typical reflection planes characteristic of cellulose I structure [39]. However, this result confirmed that the chemical process used from preparation of bleached cellulose microfibers did not alter the structure of cellulose I presented initially in the raw material. Comparing the obtained XRD patterns, it is clear to observe that the intensity of peaks increases from raw material to bleached cellulose microfibers, indicatingthe effectiveness of chemical treatment to remove all no-cellulosic compound from cellulose fibers[40].

As depicted, the alkali treatment followed by bleaching treatment remove all amorphous compounds, particularly lignin, hemicelluloses, wax and pectin [29]. It is supposed that the isolated BCM contain pure cellulose microfibers. Measuring and comparing the crystallinity index $\mathrm{Crl}$ of all fibers is further to confirm that the obtained BCM contain pure cellulose. The $\mathrm{Crl}$ values obtained for all the extract were calculated using the above-mentioned equation (1) according to Segal method [41]. It was found that the $\mathrm{Crl}$ of the prepared BCM reach the value of $60.94 \%$ which is higher than that measured for RBC $31.54 \%$ indicating that all amorphous compounds were successfully removed from cellulose fibers after the alkali followed by bleaching treatments. The $\mathrm{Crl}$ of ABC $56.87 \%$ was found to be lower than that observed for BCM $60.94 \%$. This finding confirms that alkali treatment led to partial remove of non-cellulosic compounds than bleaching treatment which remove totally all no cellulosic compounds giving as a result high crystallinity. Furthermore, similar findings were reported previously using the other raw materials. Mounir El Achaby et al [42] proved that after using the same extraction process the Crl increased from raw coffee pulp (15\%) to cellulose microfibril (52\%). Beside, Z. Kassab el al [43] investigated the effect of the same alkali and bleaching treatments to increase $\mathrm{Crl}$ of various lignocellulosic sources, it was found that the $\mathrm{Crl}$ increased from $19 \%$ for raw bagasse cane to $45 \%$ for bleached fibers and an increase from $42 \%$ for raw alfa to $71 \%$ for bleached alfa fibers was observed, while the Crl of raw red algae waste and bleached red algae was $39 \%$, and $66 \%$, of increase, respectively. However, the use of sulfuric acid hydrolysis treatments for the bleached fibers could also lead to a significant increase in the $\mathrm{Crl}$ giving as a result cellulose nanocrystal $[44,45]$.

FT-IR technique used in this study to evaluate the chemical composition change of the prepared fibers at different stages of treatments. Fig. 5. shows the FT-IR spectra of all fibers (RBC, ABC and BCM). Since all samples contain cellulose, the spectra clearly show the characteristic bands of cellulose fibers. The peak around $3441 \mathrm{~cm}^{-1}$ attributed to $\mathrm{OH}$ groups, while the presence of peaks at $2914 \mathrm{~cm}^{-1}$ ascribed to $\mathrm{C}-\mathrm{H}$ symmetrical stretching[46]. However, the band at $1645 \mathrm{~cm}^{-1}$ is assigned to the $\mathrm{O}-\mathrm{H}$ stretching and bending vibrations of the adsorbed water [22]. The peak at $1429 \mathrm{~cm}^{-1}$ is assigned to $\mathrm{CH}_{2}$ symmetric bending of cellulose [47]. The presence of peaks at $1371 \mathrm{~cm}^{-1}$ and at $1315 \mathrm{~cm}^{-1}$ are attributed to the skeletal vibration of $\mathrm{C}-\mathrm{O}$ and $\mathrm{C}-\mathrm{H}$

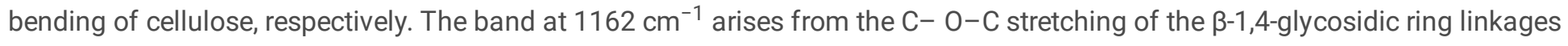
between the D-glucose units in cellulose[48]. Also, the peaks at 1031 and $894 \mathrm{~cm}^{-1}$ are ascribed to $\mathrm{C}-0$ stretching vibrations, and to the glycosidic- $\mathrm{CH}$ deformation with a ring vibration between glucoses unities in cellulose structure. The band at $621 \mathrm{~cm}^{-1}$ is attributed to the out of plane deformation of $\mathrm{C}-\mathrm{H}$. The aforementioned bands indicates clearly the presence of cellulose in all prepared samples[49]. 
Generally, the peaks assigned to hemicellulose and lignin molecules disappeared BCM. In fact, the presence of peak at 1741 $\mathrm{cm}^{-1}$ only in RBC and $\mathrm{ABC}$ curves is an excellent indication that prove lignin and hemicellulose are removed successfully after alkali and bleaching process, in fact the band at $1741 \mathrm{~cm}^{-1}$ is attributed to the acetyl and uronic ester groups of hemicellulose or to the ester linkage of carboxylic groups of ferulic and $p$-coumaric acid residues of lignin. In addition to that the peaks at 1514 $\mathrm{cm}^{-1}$ and $1247 \mathrm{~cm}^{-1}$ presented in RBC curve are attributed to $\mathrm{C}=\mathrm{C}$ stretching vibrations from the aromatic ring and $\mathrm{C}-\mathrm{O}$ out-ofplane stretching vibration of the aryl group in lignin or hemicellulose, respectively[22]. The obtained results confirmed the successful removal of non-cellulosic components such as lignin and or hemicellulose from cellulose fibers. At this stage, this finding confirms that alkali and the bleaching treatments were effective to remove non-cellulosic compounds giving as result pure cellulose fibers [43].

Thermal stability of raw, alkali and bleached cellulosic fibers were studied using TGA/DTG analysis. It is worth noting that the degradation of lignocellulosic materials starts with degradation of hemicellulose at low temperature followed by the decomposition of cellulose and lignin[50]. Fig. 6. shows the obtained TGA and DTG curves for all studied fibers. From the obtained result, all fibers showed clearly the appearance of a slight weight loss around $98^{\circ} \mathrm{C}$ indicating evaporation of water [51]. Regarding RBC curve, the thermal decomposition occurs in different steps, due to the decomposition of different lignocellulosic elements. Contrary, $\mathrm{ABC}$ and $\mathrm{BCM}$ curves showed one main loss that corresponds to cellulose decomposition characterized by a single peak centred at 316 and $326^{\circ} \mathrm{C}$, respectively.

RBC undergoes two weight loss, the first one occurs in the range $168-296^{\circ} \mathrm{C}$ (with a maximum of $215^{\circ} \mathrm{C}$ ) attributed mainly to hemicellulose and lignin decomposition, while the second degradation occurs in the range of $290-380^{\circ} \mathrm{C}$ (with a maximum of $314^{\circ} \mathrm{C}$ ) ascribed to the cellulose degradation. However, the ABC and BCM DTG curves in the range $212-367^{\circ} \mathrm{C}$ with a maximum of 316 and $326^{\circ} \mathrm{C}$, respectively. The decomposition of cellulose can be explained by dehydration, decarboxylation, depolymerisation and decomposition of glycosyl units giving as result charred residue. This finding clearly indicates the effective removal of hemicelluloses and lignin from raw material after chemical treatments [42].

\subsection{Composites characterization}

\subsubsection{Chemical structure}

Figure 7. shows FT-IR spectra of neat PP and PP/SEBS-g-MA-BCM composite. The objective of FT-IR in this part is to investigate the effect of coupling agent to enhance the interface adhesion between bleached cellulose fibers and PP matrix. FT-IR spectra show a clear difference between neat PP and PP/SEBS-g-MA-BCM, this difference is attributed to the presence of cellulose fibers and coupling agent within polymer matrix. The presence of band at $3365 \mathrm{~cm}^{-1}$ attributed to the presence of hydroxyl groups in composite, this finding indicates that there is a free $\mathrm{OH}$ functional group on the surface of cellulose fibers, which are desired to react with the coupling agent. However, the three peaks observed 1743,1641 and $1543 \mathrm{~cm}^{-1}$ are attributed to the ester bonds, mainly these strong ester bonds are originated from the interaction between hydroxyl groups presented on the surface of cellulose fibers and the maleic anhydride groups grafted on the surface of PP chains[20,24]. This finding confirms that the addition of compatibilizer agent improve significantly interfacial adhesion of composites by creating chemical bridge between cellulose fibers and matrix.

\subsubsection{Thermal stability analysis}

Thermogravimetric analysis was carried out in this work to study the effect of fibers loading and coupling agent on the thermal stability of the manufactured composites. The plotted thermal decomposition and thermal parameters of all composite are depicted in Fig. 8. and Table 1, respectively. Thermal stability of the reinforced composites and neat PP are studied using TGA/DTG analysis under atmospheric conditions starting from 27 to $700^{\circ} \mathrm{C}$. Fig. 8. shows the thermal degradation of composites as chemical treatments and fibers loading change. For this purpose, in the rage of temperature starting from 50 to $350^{\circ} \mathrm{C}$ DTA peaks appear to be made up of several smaller peaks, indicating the multiple exothermic degradation reactions of water, hemicelluloses, pectin, lignin and cellulose. The major weight loss corresponds to the thermal decomposition of the elaborated composite ranging from 350 to $500^{\circ} \mathrm{C}$. Generally, all spectra show a downward shift in temperature decomposition when fibers are incorporated in the PP matrix. A slight decrease in thermal stability is observed for composites with $2.5,5,10$

Page $7 / 24$ 
wt.\% fibers content and with coupling agent. Thus, this finding contrasts with what was expected, as it was thought that the composites containing fibers would increase thermal stability than neat polymer matrix. In fact, this decrease can be attributed to the high shear and frictional forces that occur between the polymer matrix and fibers as well as coupling agent during extrusion are thought to have caused breakage of the polymeric chains, resulting in a decrease in thermal stability of the composite[20]. Otherwise, despite the use of coupling agent which is expected to increase thermal degradation of the reinforced composites. Indeed, our finding are in contrast to a previous studies which report that poor thermal stability can be negated by the use of coupling agent [52-54].

Table 1

Thermal degradation of PP, RBC/PP, ABC/PP, BCM/PP and PP/SEBS-g-MA-BCM composites.

\begin{tabular}{|lllllllllllllllll|l|}
\hline Samples & \multicolumn{1}{l}{ RBC/PP } & \multicolumn{4}{c}{ ABC/PP } & \multicolumn{4}{c|}{ BCM/PP } & \multicolumn{4}{c|}{ PP/SEBS-g-MA-BCM } \\
\hline $\begin{array}{l}\text { Fibers } \\
\text { wt.\% }\end{array}$ & 0 & 2.5 & 5 & 10 & 0 & 2.5 & 5 & 10 & 0 & 2.5 & 5 & 10 & 0 & 2.5 & 5 & 10 \\
\hline $\begin{array}{l}\mathrm{T}_{\max } \\
\left({ }^{\circ} \mathrm{C}\right)\end{array}$ & 475 & 455 & 446 & 429 & 475 & 453 & 455 & 441 & 475 & 452 & 455 & 446 & 475 & 457 & 452 & 451 \\
\hline
\end{tabular}

\subsubsection{Tensile properties}

Figure 9. shows the effect of chemical treatments and fibers loading on the evolution of young's modulus of different composites. As expected, the incorporation of raw, alkali and bleached cellulose fibers within PP matrix increase the Young's modulus of the composites compared to neat PP. As proved by ANOVA analysis that all reinforced composites show a significant difference compared to neat PP. Generally, all type of composite shows a significant increase in the values of Young's modulus with the increase of fiber content. This increase is due to the high fibers tensile modulus compared to neat PP. In fact, a slight increase observed in Young's modulus for RBC/PP. Marked increase is observed RBC/PP when compared to neat PP (482.52 MPa \pm 22.00$)$ instead of (709.77 MPa \pm 5.57$)$, (770.63 MPa \pm 12.97$)$ and (778.65 MPa \pm 5.16$)$ at 2.5, 5, $10 \mathrm{wt} . \%$, respectively. As a result, PP reinforced with raw fibers show a gain of $47.09 \%, 59.70 \%$ and $61.37 \%$ for $2.5,5,10$ wt.\%, respectively. Regarding the alkali treated fibers, a significant enhancement was achieved when compared to neat PP, this increase is attributed to the removal of non-cellulosic components found at the surface giving as result individual fibers that have higher tensile modules as proved by SEM observation, X-ray diffraction, FTIR and TDA/TGA. Young's modulus increases from (482.52 MPa \pm 22.00$)$ for neat PP up to a maximum of (775.03 MPa \pm 27.77$)$, (765.93 MPa \pm 4.63$)$ and (783.43 MPa \pm $16.31)$ at $2.5,5,10 \mathrm{wt} . \%$, respectively. The obtained results correspond to a gain of $60.62,58.73$ and $62.36 \%$ for $2.5,5,10 \mathrm{wt} . \%$, respectively. Concerning PP reinforced with cellulose microfibers, a significant increase observed from (482.52 MPa \pm 22.00$)$ neat PP to (793.44 MPa \pm 6.07$)$, (811.37 MPa \pm 8.47$)$ and (827.02 MPa \pm 9.20$) \mathrm{BCM} / \mathrm{PP}$ at 2.5, 5, $10 \mathrm{wt} . \%$, respectively. Corresponding to a gain of $65.47 \%, 68.15 \%$ and $71.39 \%$ for $2.5,5,10 \mathrm{wt} . \%$, respectively. These finding is attributed to the excellent compatibility between the cellulose fiber and the hydrophobic matrix (PP) as well as the elimination of amorphous components using alkaline treatment via sodium hydroxide, followed by bleaching treatment in order to ensure the total elimination of lignin which is an amorphous elements in lignocellulosic materials [55-57]. It is worth to notice that the interactions between the PP and the hydroxyl groups on cellulosic fibers are enhanced as the fiber loading increase. Similar finding achieved using coupling agent for BCM/PP, an increase in Young's modulus with fiber content is marked, until it reached maximum point for PP/SEBS-g-MA-BCM (833.36 MPa \pm 6.57$)$, (844.94 MPa \pm 9.98$)$ and (844.77 MPa \pm 7.54$)$ at 2.5, 5, 10 wt.\%, respectively. This finding corresponds to a gain of $72.70 \%, 75.10 \%$ and $75.07 \%$ compared to neat PP, respectively. These results can be explained with the importance of the coupling agent (SEBS-g-MA) to enhance the interfacial adhesion between fibers and PP matrix. However, this improvement is obtained through the creation of strong ester bonds between the hydroxyl groups presented on the surface of cellulose fibers and the maleic anhydride molecules grafted to PP chains. These results are in concordance with FTIR analysis Fig. 7. which shows the presence of ester bonds in the IR spectra at 1743,1641 and $1543 \mathrm{~cm}^{-1}$ for compatibilized composite. As a result this study is in concordance with a previous work, which reported that the use of cellulose microfibers and coupling agent enhances the mechanical properties of composites due to the high rigidity of fibers [58]. 
Figure 10 illustrates the effect of fibers loading and chemical treatments on tensile strength of the elaborated composites compared to neat PP. From the obtained results, it was found that tensile strength significantly increased with incorporation of fibers at different loading. Indeed, when raw fibers were added within PP matrix (28.69MPa \pm 0.93$)$, the tensile strength increased to $(30.86 \mathrm{MPa} \pm 0.30),(31.52 \mathrm{MPa} \pm 0.64),(30.64 \mathrm{MPa} \pm 0.13)$ at $2.5,5$ and $10 \mathrm{wt} . \%$, respectively, corresponding to a gain of 7.56 , 9.86 and $6.76 \%$, respectively, compared to neat PP. This enhancement is attributed to the high adhesion between raw fibers and PP matrix. Furthermore, after carrying out alkali treatment all non-cellulosic compounds such as lignin and hemicellulose were successfully removed from cellulose fibers, which is expected to give excellent adhesion between PP matrix and the functional groups presented on the surface of cellulose (hydroxyl groups). In fact, alkali treated fibers show a significant improvement in the value of tensile strength. An important increase from (28.69MPa \pm 0.93$)$ neat PP to (32.26MPa \pm 0.79$),(31.65 \mathrm{MPa} \pm 0.38)$ and $(31.12 \mathrm{MPa} \pm 0.13)$ at $2.5,5$ and $10 \mathrm{wt}$. \%, respectively, corresponding to a gain of $12.44,10.31$ and $8.46 \%$, respectively. The bleaching treatment was performed to remove the residual lignin and hemicellulose molecules remained in alkali cellulose fibers. PP reinforced with cellulose microfibers showed a remarkable increase in tensile strength for all composite, as it increases from $(28.69 \mathrm{MPa} \pm 0.93)$ neat PP to (32.57MPa \pm 0.10$),(31.96 \mathrm{MPa} \pm 0.20)$ and $(31.04 \mathrm{MPa} \pm 1.30)$ at $2.5,5$ and 10 wt.\%, respectively, corresponding to a gain of $13.52,11.39$ and $8.19 \%$, respectively. However, the use of coupling agent can lead to significant enhance in tensile strength. For this purpose, the addition of Styrene-Ethylene-Butadiene-Styrene grafted with Maleic Anhydride (SEBS-g-MA) as a coupling agent in composites reinforced with cellulose microfibers lead to a slight increase contrasting to that without coupling agent. Comparing the compatibilized composites with neat rubber matrix PP, a significant increase is achieved from (28.69MPa \pm 0.93$)$, neat PP to (31.95MPa \pm 0.31$),(32.54 \mathrm{MPa} \pm 0.20)$ and $(32.57 \mathrm{MPa} \pm 0.73)$ at 2.5, 5 and $10 \mathrm{wt} . \%$, respectively, corresponding to a gain of $13.52,11.39$ and $8.19 \%$, respectively. Therefore, the effect of different chemically treated bagasse fibers at different loading led to significant increase in the values of tensile strength, as evidenced by the ANOVA analysis which shows a significant difference between all composites and pure PP. However, the obtained result confirms the good interfacial adhesion generating better stress transfer under tensile load.

Figure 11. shows the effect of fibers loading and chemical treatments of surface fibers on elongation at break. In fact, in this work elongation at break was determined aiming to investigate the ductile behavior of the elaborated composites. The obtained results clearly show a significant decrease in elongation at break for all reinforced composite compared to that obtained for neat PP. This decrease in elongation at break from raw fibers to compatibilized composite explained by to the rigid behavior of the fillers (low elasticity). The use of rigid fibers to prepare composite materials in thermoplastic matrix leads to less deformability due to its low plastic energy that can be absorbed. However, from the results already published in the literature, the use of bagasse fibers as reinforcement for thermoplastic matrix led to remarkable decrease in elongation at break [59-63]. Also, this finding is in accordance with the literature particularly for those that prepare hybrid materials based on two natural fillers, for instance, Boujmal et al have been reported alfa fibers and clay particles hybrid composites based on polypropylene led to significant decrease in elongation at break[64]. Additionally, the same trend was also reported several studies especially polymer reinforced with cellulose nanocrystals $[65,66]$. Regarding our results, when compared pure PP a decrease of $11.52 \%, 20.12 \%$ and $33.11 \%$ at 2.5, 5, $10 \mathrm{wt}$ \% for RBC, respectively. On one hand, similar decrease is observed after alkali treatment of fibers. The obtained results show a slight decrease of about $14.80 \%, 17.10 \%$ and $40.20 \%$ at $2.5,5,10 \mathrm{wt}$ \% fibers loading compared to neat PP. On the other hand, PP reinforced with bleached cellulose show also a significant decrease about $3.85 \%, 16.50 \%$ and $41.26 \%$ at 2.5, 5, 10 wt.\% compared to neat PP. Besides, the use of coupling agent within PP reinforced with bleached cellulose as a significant decrease was observed about $27.96 \%, 28.14 \%$ and $41.48 \%$ at $2.5,5,10 \mathrm{wt}$. compared to neat PP. The ANOVA analysis proves that all reinforced composites show a significant difference compared to neat PP. In fact, these results can be ascribed to the excellent interfacial adhesion, confirming that the chemical treatment and modification improves the fiber and matrix adhesion.

Toughness of the elaborated composites is an important parameter, which allows to identify the ability of material to absorb mechanical energy up to the point of failure. In fact, the toughness is the area under the stress-strain curve, can be calculated by integrating the stress-strain curve. Fig. 12. shows the effect of fibers loading and surface modification on toughness of the elaborated composite as compared to neat PP. Generally, toughness of the reinforced composites decreases as fibers loading increase at different treatments. From the obtained results, the maximum strain of neat PP $\left(10.75 \mathrm{MJ} / \mathrm{m}^{3} \pm 0.45\right)$, reduced to $\left(7.55 \mathrm{MJ} / \mathrm{m}^{3} \pm 0.22\right),\left(6.99 \mathrm{MJ} / \mathrm{m}^{3} \pm 0.61\right)$ and $\left(5.59 \mathrm{MJ} / \mathrm{m}^{3} \pm 0.43\right)$ when $2.5,5$ and $10 \mathrm{wt} . \%$ of RBC were added, which 
corresponds to a decrease of $29.76,34.97$ and $48 \%$ in comparison with neat PP, respectively. However, ABC fibers show also a significant decrease compared to neat PP $\left(10.75 \mathrm{MJ} / \mathrm{m}^{3} \pm 0.45\right)$, decrease to $\left(7.69 \mathrm{MJ} / \mathrm{m}^{3} \pm 0.35\right),\left(7.37 \mathrm{MJ} / \mathrm{m}^{3} \pm 0.81\right)$ and $(5.61$ $\left.\mathrm{MJ} / \mathrm{m}^{3} \pm 1.01\right)$ at $2.5,5$ and $10 \mathrm{wt}$.\%, showing a decrease about $28.46,31.44,47.81 \%$, compared to neat PP, respectively. the same trend was observed for PP reinforced with cellulose microfibers, a significant decrease in toughness was observed due to excellent adhesion between matrix and cellulose fibers, a decrease to (8.99 MJ/m³ \pm 0.91$),\left(7.15 \mathrm{MJ} / \mathrm{m}^{3} \pm 0.96\right)$ and $\left(4.19 \mathrm{MJ} / \mathrm{m}^{3}\right.$ \pm 0.57 ) at $2.5,5$ and $10 \mathrm{wt} . \%$, corresponding to a decrease about $16.37,33.48,76.02$ compared to neat PP, respectively. The use of coupling agent (SEBS-g-MA) in the PP reinforced by cellulose fibers led to significant decrease in toughness due to its strong ester bond with the hydroxyl groups of cellulose fibers. In fact, a considerable decrease to $\left(6.42 \mathrm{MJ} / \mathrm{m}^{3} \pm 2.19\right),\left(6.39 \mathrm{MJ} / \mathrm{m}^{3}\right.$ $\pm 1.17)$ and $\left(5.58 \mathrm{MJ} / \mathrm{m}^{3} \pm 0.37\right)$ at $2.5,5$ and $10 \mathrm{wt}$.\%, corresponds to a decrease about $40.27,40.55,48.09 \%$ compared to neat PP, respectively. The ANOVA analysis proves that all reinforced composites show a significant difference compared to neat PP.

\subsubsection{Hardness properties}

Figure 13. shows the effect of fibers loading and chemical treatment of the prepared fibers on the hardness properties of the elaborated composites. In fact, fibers content and surface treatments led to significant increase in the hardness values of the composites. Indeed, comparing all elaborated composite no significant difference in hardness as fibers loading increase, this stability is related to the ability of fibers to increase the resistance of matrix to deform plastically. Also, smaller particles can achieve better adhesion and distribution than that of small fibers.

The hardness values of PP reinforced with RBC fibers at 2.5, 5 and 10 wt.\% were enhanced slightly corresponding to an increase of about $15.29,16.44,16.81 \%$, respectively, compared to neat PP. However, ABC fibers also show a significant increase at $2.5,5$ and 10 wt.\%, the hardness values show a gain in comparison with neat PP of about 14.67, 15.17,17.48\%, respectively. Moreover, the incorporation of cellulose fibers in PP matrix, the hardness value of the composites at different fibers loading 2.5, 5 and 10 wt.\% presenting an important increase of 14.57, 15.85, 18.66\%, respectively. As expected, the addition of coupling agent might have improved the interfacial interaction among the constituents of composites (matrix and cellulose fibers). The obtained result shows an enhancement at 2.5, 5 and 10 wt.\% about 14.24, 15.71, 16.10\%, respectively. The ANOVA analysis proves that all reinforced composites show a significant difference compared to neat PP. In fact, the enhancements in hardness of the elaborated composites compared to neat PP indicate the good interfacial interaction between the prepared fibers and polymer matrix as well as coupling agent. However, this could also be attributed to the lower aspect ratio and disorientation of fibers along the matrix giving as result composites stiffer and more resistant to deformation.

\subsubsection{Torsion properties.}

Figure 14. shows the evolution of torsion modulus $\mathrm{G}^{*}$ of all composite and neat $\mathrm{PP}$ in the frequency range $0.1 \mathrm{~Hz}$ to $40 \mathrm{~Hz}$. It is worth noting that the curves steady increase of torsion modulus from low to highest frequency. This increase is due the viscoelastic behavior of polymer composites. This finding means that PP reinforced with different treated and modified fibers behave more like elastic solids as frequency increases. On one hand, PP reinforced with bleached cellulose microfibers shows an increase in complex modulus than all composites and neat PP. This increase in $\mathrm{G} *$ for PP/BCM is related to the effect of bleaching treatment to give fibrils more flexible under a twisting force. On the other hand, both curves for PP reinforced with RBA and $A B C$ almost enough to be overlap. This finding is further to explain that alkali treatment removes partially no-cellulosic compounds from RBA resulting in lignin permeates inside cellulose fibers and giving as fibers more rigid than raw materials. Thus, slowing down rotation with the applied twisting movement. Nevertheless, the interfacial adhesion between bleached cellulose microfibers and matrix can be improved using SEBS-g-MA as a coupling agent. In this aspect, PP reinforced with SEBSg-MA-BCM exhibit low torsion modules compared to all composite, particularly in comparison with PP/BCM which indicate clearly a big difference and prove the effect of coupling agent to improve fibers adhesion with polymer matrix. This drop in $\mathrm{G}^{*}$ is ascribed to the rigid character of PP/ SEBS-g-MA-BCM as result a slow rotation response for all applied twisting.

The elastic and viscous behaviours of the reinforced composite can be obtained by studying the effect of the applied frequencies on different type of PP/fibers composites at various fibers loading. For this purpose, Fig. 15. the evolution of tan $\delta$ versus frequencies from 0.1 to $40 \mathrm{~Hz}$ and particles loading 0 to $10 \mathrm{wt}$.\%. The obtained result shows that in case of all composites the values of $\tan \delta$ decrease with increasing frequencies. This finding clearly indicates the predominance of elastic

Page $10 / 24$ 
character over than plastic character. Therefore, based on fibers loading tan $\delta$ show a slight decrease as fibers loading increase, indicating that the prepared fibers are more rigid into polymer which restrained the segment mobility of molecules chain of PP. Nevertheless, the use of rigid fibers significantly increases storage modulus and decrease the viscous elastic lag between the stress and the strain. Actually, our finding is in good agreement with previous work which investigate the effect of rigid fibers on $\tan \delta[67,68]$.

\section{Conclusions:}

In this study, we presented the potential use of bagasse cane by-product for the reinforcement of polypropylene matrix. However, based on our finding fibers bagasse cane by-product could be a promising raw material for the preparation of bio-based composites and their industrialization. Generally, the use of alkali and bleaching chemical process allows possibility for fibers surface treatment resulting in alkali and microfibers cellulose, respectively. Hence, all fibers characterization proves the effectiveness to remove all no-cellulosic compounds from raw bagasse cane. The elaborated composites show a significant enhancement in mechanical and rheological properties due to the good interfacial adhesion between fibers and matrix. While the use of all fibers led to significant decrease in thermal stability compared to neat PP. In fact, further studies are required to improve well the mechanical properties of composite PP as well as its thermal stability. This work demonstrates the feasibility of elaborating an eco-friendly made from industrial by-product via twin-screw extrusion followed by injection molding.

\section{Declarations}

Acknowledgements: The authors gratefully acknowledge Analysis and Characterization center (CAC) at Cady Ayyad University; Marrakech; Morocco. The financial assistance of the Moroccan National Center for Scientific and Technical Research (CNRST) toward this research is hereby acknowledged. Thanks to Abou El Kacem QAISS from Moroccan Foundation for Advanced Science, Innovation and Research (MAScIR) for his help to elaborate and characterize all our composites.

Declaration of interest: The author(s) received no financial support for the research, authorship, and/or publication of this article.

Conflict of interest: The authors declare that there is no conflict of competing interest that could have appeared to influence the work reported in this paper.

Ethical Approval: This article does not contain studies with human participants or animals.

Data availability statement: The authors confirm that the data supporting findings of this work are available within the article. Raw data that support the findings of this study are available from the corresponding authors, upon reasonable request.

\section{References}

1. Mangalgiri, P.D.: Composite materials for aerospace applications. Bull. Mater. Sci. 1999. https://doi.org/10.1007/BF02749982

2. Cole, G.S., Sherman, A.M.: Light weight materials for automotive applications. Mater. Charact. 1995. https://doi.org/10.1016/1044-5803(95)00063-1

3. Kokkinis, D., Schaffner, M., Studart, A.R.: Multimaterial magnetically assisted 3D printing of composite materials. Nat. Commun. 2015. https://doi.org/10.1038/ncomms9643

4. Ramakrishna, S., Mayer, J., Wintermantel, E., Leong, K.W.: Biomedical applications of polymer-composite materials: A review. Composites Science and Technology 2001. https://doi.org/10.1016/S0266-3538(00)00241-4

5. Moubarik, A., Grimi, N., Boussetta, N.: Structural and thermal characterization of Moroccan sugar cane bagasse cellulose fibers and their applications as a reinforcing agent in low density polyethylene. Composites Part B: Engineering 2013. https://doi.org/10.1016/j.compositesb.2013.04.040

6. Aymes-Chodur, C., Betz, N., Legendre, B., Yagoubi, N.: Structural and physico-chemical studies on modification of polypropylene and its polyphenolic antioxidant by electron beam irradiation. Polym. Degrad. Stab. 2006.

Page $11 / 24$ 
https://doi.org/10.1016/j.polymdegradstab.2005.05.013

7. John, M.J., Anandjiwala, R.D.: Recent developments in chemical modification and characterization of natural fiberreinforced composites. Polym. Compos. 2008. https://doi.org/10.1002/pc.20461

8. Boussetta, A., Ablouh, E.H., Benhamou, A.A., Taourirte, M., Moubarik, A.: Valorization of Moroccan brown seaweeds: Elaboration of formaldehyde-free particleboards based on sodium alginate-corn-starch - Mimosa tannin wood adhesives. Int. J. Adhes. Adhes. 108, 102894 (2021). https://doi.org/10.1016/j.ijadhadh.2021.102894

9. Bledzki, A.K., Gassan, J.: Composites reinforced with cellulose based fibres. Prog. Polym. Sci. 1999. https://doi.org/10.1016/S0079-6700(98)00018-5

10. Kabir, M.M., Wang, H., Aravinthan, T., Cardona, F., Lau, K.-T.: Effects of Natural Fibre Surface on Composite Properties: a Review. Energy, Environment and Sustainability (2007)

11. Kabir, M.M., Wang, H., Lau, K.T., Cardona, F.: Chemical treatments on plant-based natural fibre reinforced polymer composites: An overview. Composites Part B: Engineering 2012. https://doi.org/10.1016/j.compositesb.2012.04.053

12. Ait Benhamou, A., Boussetta, A., Kassab, Z., Nadifiyine, M., Hamid Salim, M., Grimi, N., et al.: Investigating the characteristics of cactus seeds by-product and their use as a new filler in phenol formaldehyde wood adhesive. Int. J. Adhes. Adhes. 2021;110. https://doi.org/10.1016/j.ijadhadh.2021.102940

13. Cellulose Fibers: Bio- and Nano-Polymer Composites. 2011. https://doi.org/10.1007/978-3-642-17370-7

14. Benhamou, A., Boussetta, A., Grimi, N., Idrissi, M., El, Nadifiyine, M., Barba, F.J., et al.: Characteristics of cellulose fibers from Opuntia ficus indica cladodes and its use as reinforcement for PET based composites. J. Nat. Fibers 2021. https://doi.org/10.1080/15440478.2021.1904484

15. Mohanty, A.K., Wibowo, A., Misra, M., Drzal, L.T.: Effect of process engineering on the performance of natural fiber reinforced cellulose acetate biocomposites. Compos. Part A: Appl. Sci. Manufac., 2004.

https://doi.org/10.1016/j.compositesa.2003.09.015

16. Van Voorn, B., Smit, H.H.G., Sinke, R.J., De Klerk, B.: Natural fibre reinforced sheet moulding compound. Composites - Part A: Applied Science and Manufacturing 2001. https://doi.org/10.1016/S1359-835X(01)00085-9

17. Ait Benhamou, A., Kassab, Z., Nadifiyine, M., Salim, H.M., Sehaqui, H., Moubarik, A., et al.: Extraction, Characterization and Chemical Functionalization of Phosphorylated Cellulose derivatives from Giant Reed Plant. Cellulose 2021;6. https://doi.org/10.1007/s10570-021-03842-6

18. Ramesh, M., Palanikumar, K., Reddy, K.H.: Plant fibre based bio-composites: Sustainable and renewable green materials. Renew. Sustain. Energy Rev. 79, 558-584 (2017). https://doi.org/10.1016/J.RSER.2017.05.094

19. Zwawi, M.A.: Review on Natural Fiber Bio-Composites, Surface Modifications and Applications. Molecules 2021, Vol 26, Page 404 2021;26:404. https://doi.org/10.3390/MOLECULES26020404

20. Ait Benhamou, A., Boussetta, A., Nadifiyine, M., Moubarik, A.: Effect of alkali treatment and coupling agent on thermal and mechanical properties of Opuntia ficus-indica cladodes fibers reinforced HDPE composites. Polym. Bull. 2021. https://doi.org/10.1007/s00289-021-03619-8

21. Le Moigne, N., Otazaghine, B., Corn, S., Angellier-Coussy, H., Bergeret, A.: Modification of the Interface/Interphase in Natural Fibre Reinforced Composites: Treatments and Processes 2018:35-70. https://doi.org/10.1007/978-3-319-71410-3_3

22. Kassab, Z., Abdellaoui, Y., Salim, M.H., Bouhfid, R., Qaiss, A.E.K., El Achaby, M.: Micro- and nano-celluloses derived from hemp stalks and their effect as polymer reinforcing materials. Carbohyd. Polym. 2020;245. https://doi.org/10.1016/j.carbpol.2020.116506

23. Kassab, Z., Mansouri, S., Tamraoui, Y., Sehaqui, H., Hannache, H., Qaiss, A.E.K., et al.: Identifying Juncus plant as viable source for the production of micro- and nano-cellulose fibers: Application for PVA composite materials development. Ind. Crops Prod. 2020. https://doi.org/10.1016/j.indcrop.2019.112035

24. Arrakhiz, F.Z., El Achaby, M., Benmoussa, K., Bouhfid, R., Essassi, E.M., Qaiss, A.: Evaluation of mechanical and thermal properties of Pine cone fibers reinforced compatibilized polypropylene. Mater. Des. 40, 528- 535 (2012). https://doi.org/10.1016/j.matdes.2012.04.032 
25. Rumánková, L., Smutka, L.: Global sugar market-The analysis of factors influencing supply and demand 2013;LXI:463-71. https://doi.org/10.11118/actaun201361020463

26. Sahu, 0.: Assessment of sugarcane industry: Suitability for production, consumption, and utilization. Annals of Agrarian Science 2018. https://doi.org/10.1016/j.aasci.2018.08.001

27. Robak, K., Balcerek, M.: Review of second generation bioethanol production from residual biomass. Food Technology and Biotechnology 2018. https://doi.org/10.17113/ftb.56.02.18.5428

28. Rabelo, S.C., Carrere, H., Maciel Filho, R., Costa, A.C.: Production of bioethanol, methane and heat from sugarcane bagasse in a biorefinery concept. Biores. Technol. 2011. https://doi.org/10.1016/j.biortech.2011.05.081

29. Dias, M.O.S., Cunha, M.P., Jesus, C.D.F., Rocha, G.J.M., Pradella, J.G.C., Rossell, C.E.V., et al.: Second generation ethanol in Brazil: Can it compete with electricity production? Bioresource Technology 2011. https://doi.org/10.1016/j.biortech.2011.06.098

30. Tahir, H., Sultan, M., Akhtar, N., Hameed, U., Abid, T.: Application of natural and modified sugar cane bagasse for the removal of dye from aqueous solution. Journal of Saudi Chemical Society 2016. https://doi.org/10.1016/j.jscs.2012.09.007

31. Ghaderi, M., Mousavi, M., Yousefi, H., Labbafi, M.: All-cellulose nanocomposite film made from bagasse cellulose nanofibers for food packaging application. Carbohyd. Polym. 2014. https://doi.org/10.1016/j.carbpol.2014.01.013

32. Moubarik, A., Grimi, N., Boussetta, N., Pizzi, A.: Isolation and characterization of lignin from Moroccan sugar cane bagasse: Production of lignin-phenol-formaldehyde wood adhesive. Ind. Crops Prod. 2013.

https://doi.org/10.1016/j.indcrop.2012.12.040

33. Balaji, A., Karthikeyan, B., Sundar Raj, C.: Bagasse fiber - The future biocomposite material: A review. International Journal of ChemTech Research 2015

34. Boussetta, A., Benhamou, A.A., Barba, F.J., Idrissi, M.E.L., Grimi, N., Moubarik, A.: Experimental and theoretical investigations of lignin-urea-formaldehyde wood adhesive: Density functional theory analysis. Int. J. Adhes. Adhes. 104, 102737 (2021). https://doi.org/10.1016/j.jiadhadh.2020.102737

35. Arrakhiz, F.Z., Malha, M., Bouhfid, R., Benmoussa, K., Qaiss, A.: Tensile, flexural and torsional properties of chemically treated alfa, coir and bagasse reinforced polypropylene. Composites Part B: Engineering. 47, 35-41 (2013).

https://doi.org/10.1016/j.compositesb.2012.10.046

36. Segal, L., Creely, J.J., Martin, A.E., Conrad, C.M.: An Empirical Method for Estimating the Degree of Crystallinity of Native Cellulose Using the X-Ray Diffractometer. Text. Res. J. 1959. https://doi.org/10.1177/004051755902901003

37. International Organization for Standardization. ISO 527-1:2012 - Plastics - Determination of tensile properties - Part 1: General principles. Geneva 2012

38. Laaziz, S.A., Raji, M., Hilali, E., Essabir, H., Rodrigue, D., Bouhfid, R., et al.: Bio-composites based on polylactic acid and argan nut shell: Production and properties. Int. J. Biol. Macromol. 2017. https://doi.org/10.1016/j.ijbiomac.2017.05.184

39. Hernández-Varela, J.D., Chanona-Pérez, J.J., Calderón Benavides, H.A., Cervantes Sodi, F., Vicente-Flores, M.: Effect of ball milling on cellulose nanoparticles structure obtained from garlic and agave waste. Carbohyd. Polym. 2021. https://doi.org/10.1016/j.carbpol.2020.117347

40. Kassab, Z., Boujemaoui, A., Ben Youcef, H., Hajlane, A., Hannache, H., El Achaby, M.: Production of cellulose nanofibrils from alfa fibers and its nanoreinforcement potential in polymer nanocomposites. Cellulose. 26, 9567-9581 (2019). https://doi.org/10.1007/s10570-019-02767-5

41. French, A.D., Santiago Cintrón, M.: Cellulose polymorphy, crystallite size, and the Segal Crystallinity Index. Cellulose 2013. https://doi.org/10.1007/s10570-012-9833-y

42. El Achaby, M., Ruesgas-Ramón, M., Fayoud, N.E.H., Figueroa-Espinoza, M.C., Trabadelo, V., Draoui, K., et al.: Bio-sourced porous cellulose microfibrils from coffee pulp for wastewater treatment. Cellulose. 26, 3873-3889 (2019). https://doi.org/10.1007/s10570-019-02344-w

43. Kassab, Z., Ben youcef, H., Hannache, H., El Achaby, M.: Isolation of cellulose nanocrystals from various lignocellulosic materials: Physico-chemical characterization and Application in Polymer Composites Development. Materials Today: Proceedings 2019;13:964-73. https://doi.org/10.1016/j.matpr.2019.04.061

Page $13 / 24$ 
44. El Miri, N., Abdelouahdi, K., Barakat, A., Zahouily, M., Fihri, A., Solhy, A., et al.: Bio-nanocomposite films reinforced with cellulose nanocrystals: Rheology of film-forming solutions, transparency, water vapor barrier and tensile properties of films. Carbohyd. Polym. 129, 156-167 (2015). https://doi.org/10.1016/j.carbpol.2015.04.051

45. El Achaby, M., Kassab, Z., Aboulkas, A., Gaillard, C., Barakat, A.: Reuse of red algae waste for the production of cellulose nanocrystals and its application in polymer nanocomposites. Int. J. Biol. Macromol. 2018. https://doi.org/10.1016/j.ijbiomac.2017.08.067

46. Tarchoun, A.F., Trache, D., Klapötke, T.M.: Microcrystalline cellulose from Posidonia oceanica brown algae: Extraction and characterization. Int. J. Biol. Macromol. 2019. https://doi.org/10.1016/j.ijbiomac.2019.07.176

47. Fortunati, E., Puglia, D., Luzi, F., Santulli, C., Kenny, J.M., Torre, L.: Binary PVA bio-nanocomposites containing cellulose nanocrystals extracted from different natural sources: Part I. Carbohydrate Polymers 2013. https://doi.org/10.1016/j.carbpol.2013.03.075

48. Zhao, Y., Moser, C., Lindström, M.E., Henriksson, G., Li, J.: Cellulose Nanofibers from Softwood, Hardwood, and Tunicate: Preparation-Structure-Film Performance Interrelation. ACS Applied Materials and Interfaces 2017. https://doi.org/10.1021/acsami.7b01738

49. Kallel, F., Bettaieb, F., Khiari, R., García, A., Bras, J., Chaabouni, S.E.: Isolation and structural characterization of cellulose nanocrystals extracted from garlic straw residues. Ind. Crops Prod. 2016. https://doi.org/10.1016/j.indcrop.2016.04.060

50. AL-Oqla, F.M., Hayajneh, M.T., Fares, O.: Investigating the mechanical thermal and polymer interfacial characteristics of Jordanian lignocellulosic fibers to demonstrate their capabilities for sustainable green materials. J. Clean. Prod. 2019. https://doi.org/10.1016/j.jclepro.2019.118256

51. Trache, D.: Nanocellulose as a promising sustainable material for biomedical applications. AIMS Materials Science 2018. https://doi.org/10.3934/matersci.2018.2.201

52. Kim, H.S., Kim, S., Kim, H.J., Yang, H.S.: Thermal properties of bio-flour-filled polyolefin composites with different compatibilizing agent type and content. Thermochim. Acta 2006. https://doi.org/10.1016/j.tca.2006.09.013

53. Gañán, P., Mondragon, I.: Thermal and degradation behavior of fique fiber reinforced thermoplastic matrix composites. J. Therm. Anal. Calorim. 2003. https://doi.org/10.1023/A:1025830430267

54. Ray, D., Sarkar, B.K., Basak, R.K., Rana, A.K.: Thermal behavior of vinyl ester resin matrix composites reinforced with alkalitreated jute fibers. J. Appl. Polym. Sci. 2004. https://doi.org/10.1002/app.20754

55. Seki, Y.: Innovative multifunctional siloxane treatment of jute fiber surface and its effect on the mechanical properties of jute/thermoset composites. Mater. Sci. Eng., A 2009. https://doi.org/10.1016/j.msea.2009.01.043

56. Stocchi, A., Lauke, B., Vázquez, A., Bernal, C.: A novel fiber treatment applied to woven jute fabric/vinylester laminates. Compos. Part A: Appl. Sci. Manufac. 2007. https://doi.org/10.1016/j.compositesa.2006.10.010

57. Morán, J.I., Alvarez, V.A., Cyras, V.P., Vázquez, A.: Extraction of cellulose and preparation of nanocellulose from sisal fibers. Cellulose 2008. https://doi.org/10.1007/s10570-007-9145-9

58. Saba, N., Tahir, P.M., Jawaid, M.: A review on potentiality of nano filler/natural fiber filled polymer hybrid composites. Polymers 2014. https://doi.org/10.3390/polym6082247

59. Luz, S.M., Gonçalves, A.R., Del'Arco, A.P.: Mechanical behavior and microstructural analysis of sugarcane bagasse fibers reinforced polypropylene composites. Compos. Part A: Appl. Sci. Manufac. 2007.

https://doi.org/10.1016/j.compositesa.2007.01.014

60. Mulinari, D.R., Voorwald, H.J.C., Cioffi, M.O.H., da Silva, M.L.C.P., Luz, S.M.: Preparation and properties of HDPE/sugarcane bagasse cellulose composites obtained for thermokinetic mixer. Carbohyd. Polym. 2009.

https://doi.org/10.1016/j.carbpol.2008.07.028

61. Corradini, E., Ito, E.N., Marconcini, J.M., Rios, C.T., Agnelli, J.A.M., Mattoso, L.H.C.: Interfacial behavior of composites of recycled poly(ethyelene terephthalate) and sugarcane bagasse fiber. Polym. Testing 2009.

https://doi.org/10.1016/j.polymertesting.2008.11.014

62. El-Fattah, A.A., El Demerdash, A.G.M., Alim Sadik, W.A., Bedir, A.: The effect of sugarcane bagasse fiber on the properties of recycled high density polyethylene. J. Compos. Mater. 2015. https://doi.org/10.1177/0021998314561484

Page $14 / 24$ 
63. Mulinari, D.R., Voorwald, H.J.C., Cioffi, M.O.H., da Silva, M.L.C.P., da Cruz, T.G., Saron, C.: Sugarcane bagasse cellulose/HDPE composites obtained by extrusion. Composites Science and Technology 2009.

https://doi.org/10.1016/j.compscitech.2008.10.006

64. Essabir, H., Bensalah, M.O., Rodrigue, D., Bouhfid, R.: Qaiss A el kacem. A comparison between bio- and mineral calcium carbonate on the properties of polypropylene composites. Constr. Build. Mater. 134, 549-555 (2017).

https://doi.org/10.1016/j.conbuildmat.2016.12.199

65. El Achaby, M., Kassab, Z., Aboulkas, A., Gaillard, C., Barakat, A.: Reuse of red algae waste for the production of cellulose nanocrystals and its application in polymer nanocomposites. Int. J. Biol. Macromol. 106, 681-691 (2018).

https://doi.org/10.1016/j.ijbiomac.2017.08.067

66. Spagnol, C., Fragal, E.H., Witt, M.A., Follmann, H.D.M., Silva, R., Rubira, A.F.: Mechanically improved polyvinyl alcoholcomposite films using modified cellulose nanowhiskers as nano-reinforcement. Carbohyd. Polym. 191, 25-34 (2018). https://doi.org/10.1016/j.carbpol.2018.03.001

67. Arrakhiz, F.Z., El Achaby, M., Kakou, A.C., Vaudreuil, S., Benmoussa, K., Bouhfid, R., et al.: Mechanical properties of high density polyethylene reinforced with chemically modified coir fibers: Impact of chemical treatments. Mater. Des. 37, 379383 (2012). https://doi.org/10.1016/j.matdes.2012.01.020

68. Hammiche, D., Boukerrou, A., Guermazi, N., Arrakhiz, F.E.: Effects of types of PVC-g-MA on wettability and dynamical behavior of polyvinyl Chloride/Alfa composites. Materials Today: Proceedings 2020;36:10-5.

https://doi.org/10.1016/j.matpr.2020.04.675

\section{Figures}

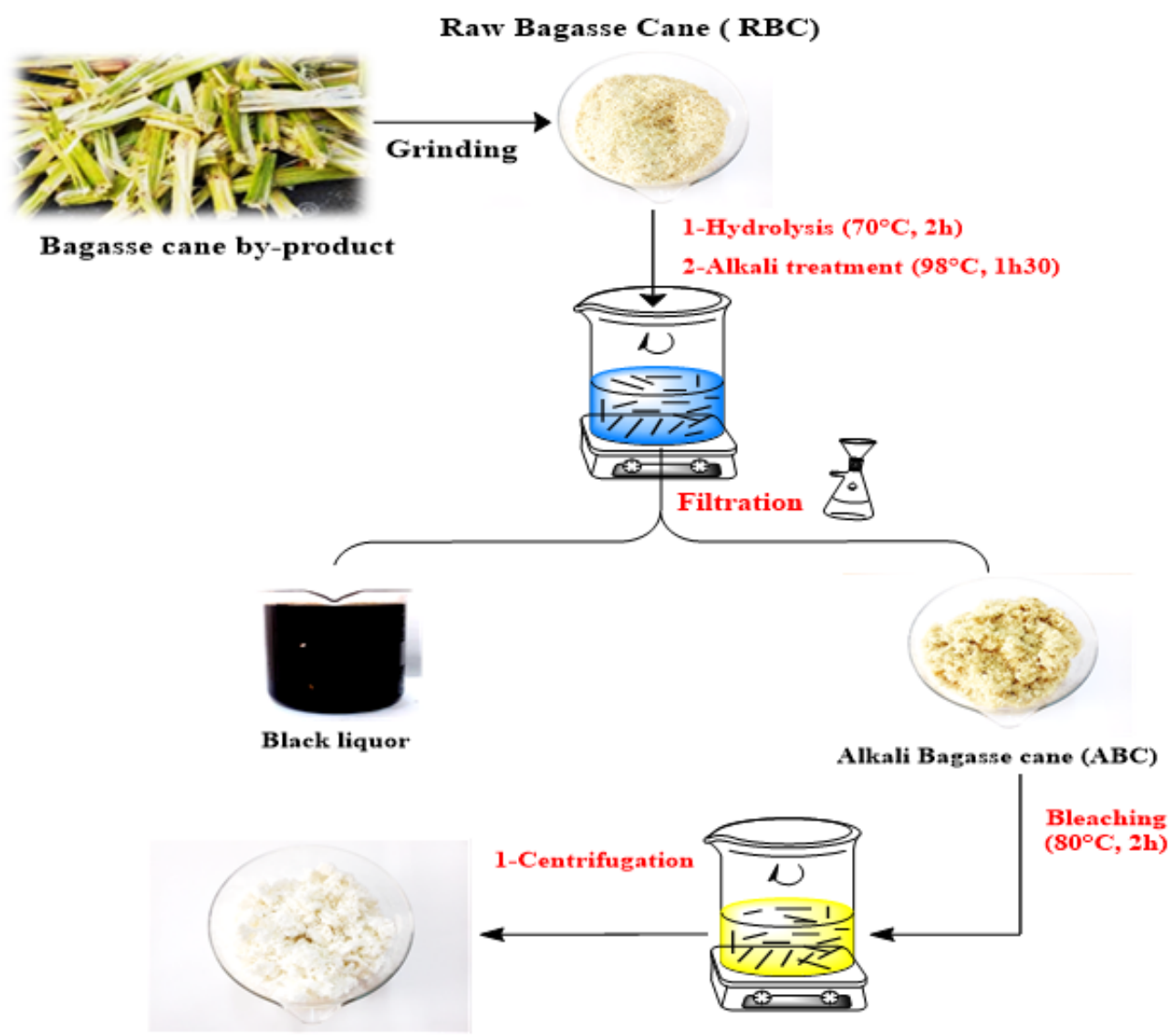

Bleached Cellulose Microfibers (BCM)

Figure 1

Page 15/24 

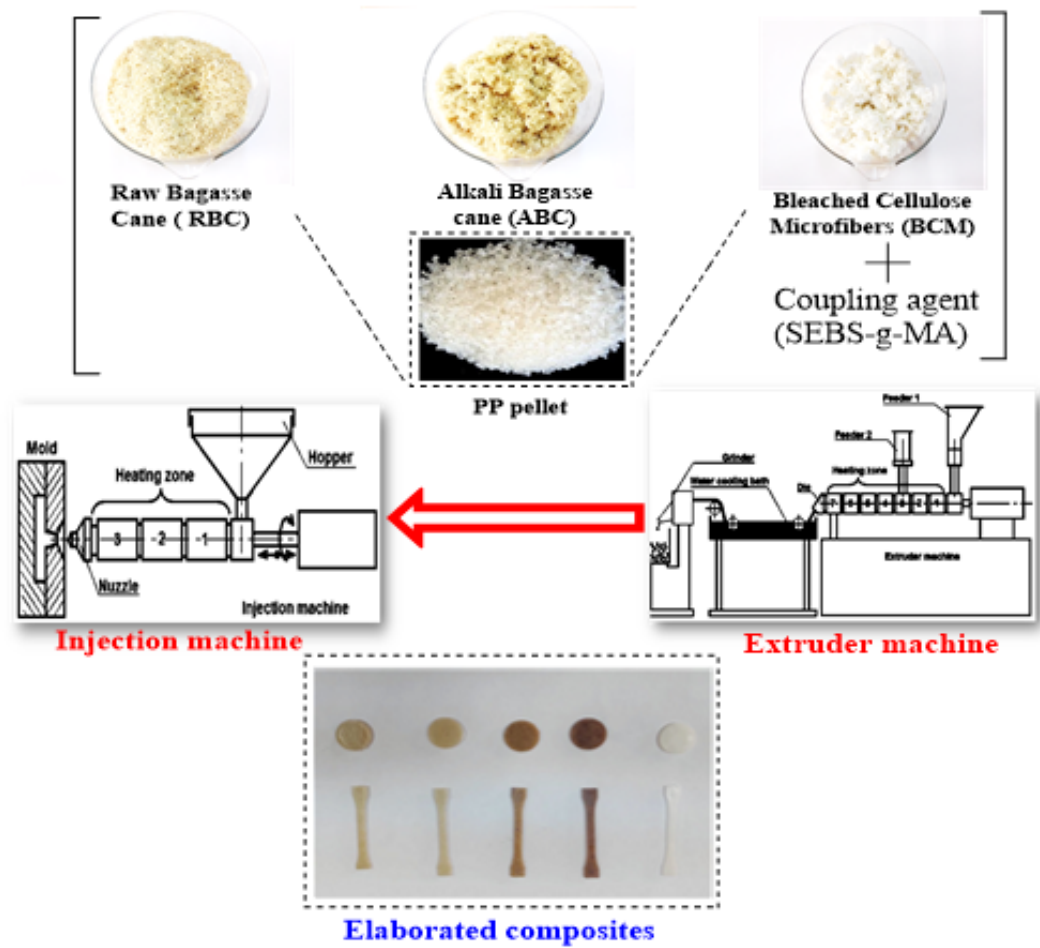

\section{Figure 2}

Scheme of different steps for preparation of composites, melt extrusion and injection molding process. 


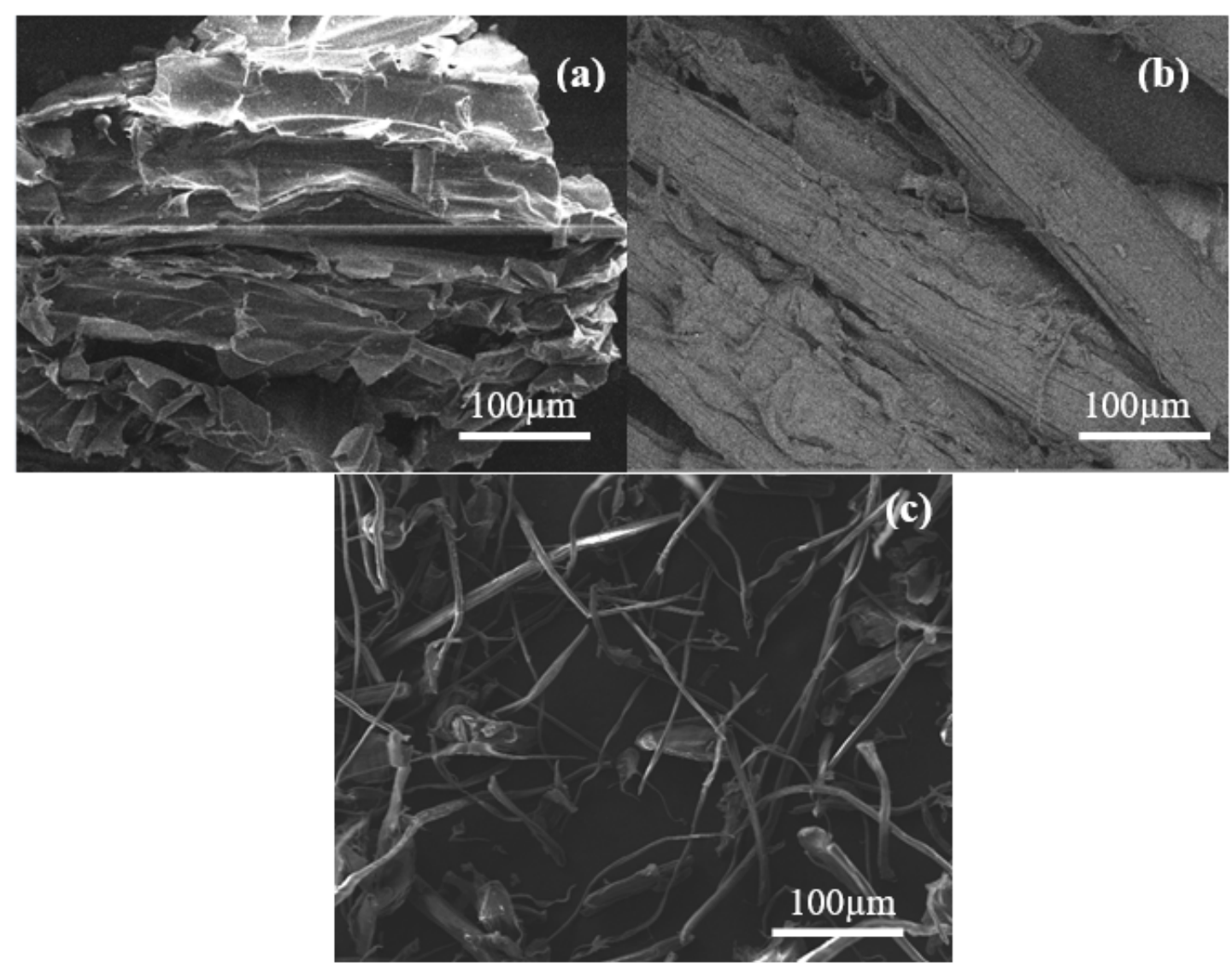

Figure 3

SEM images of RBC (a), ABC(b) and BCM (c) extracted from bagasse cane by-product.

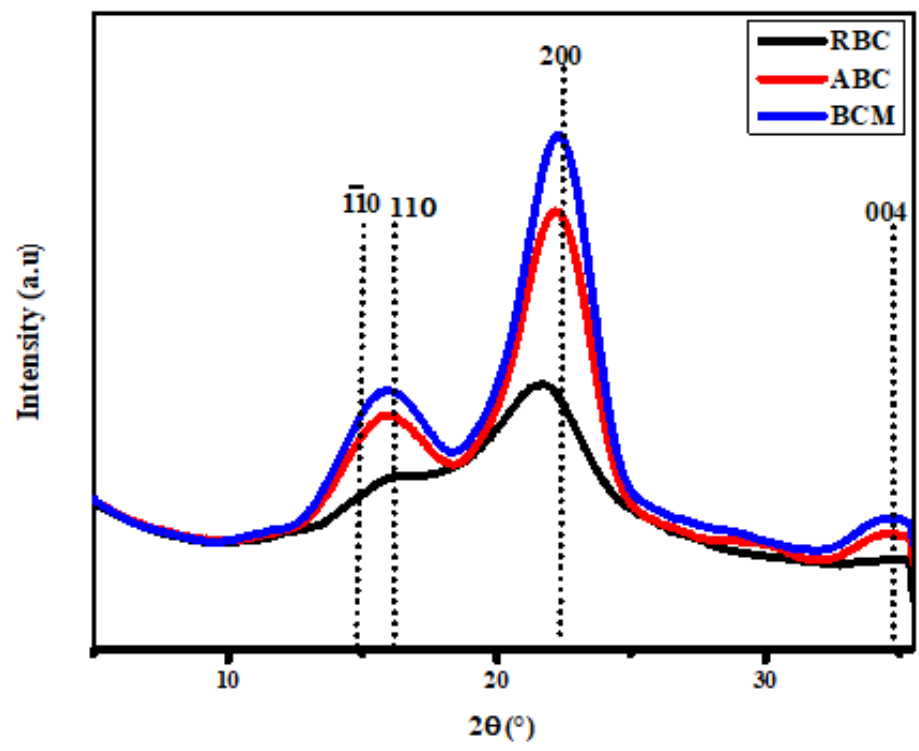

Figure 4

XRD patterns of $R B C, A B C$ and $B C$ samples. 


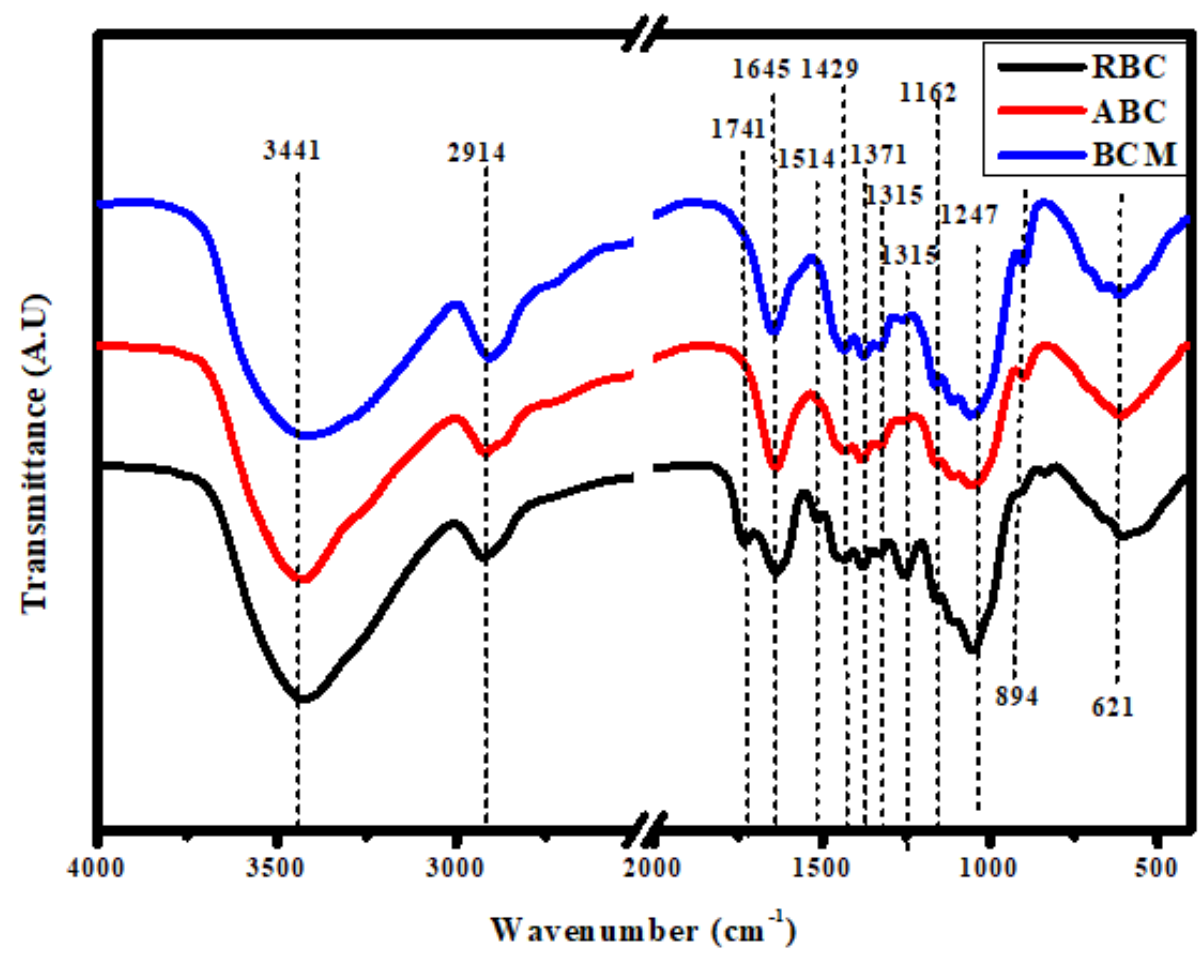

Figure 5

FT-IR spectra of RBC, $A B C$ and $B C M$ fibers.
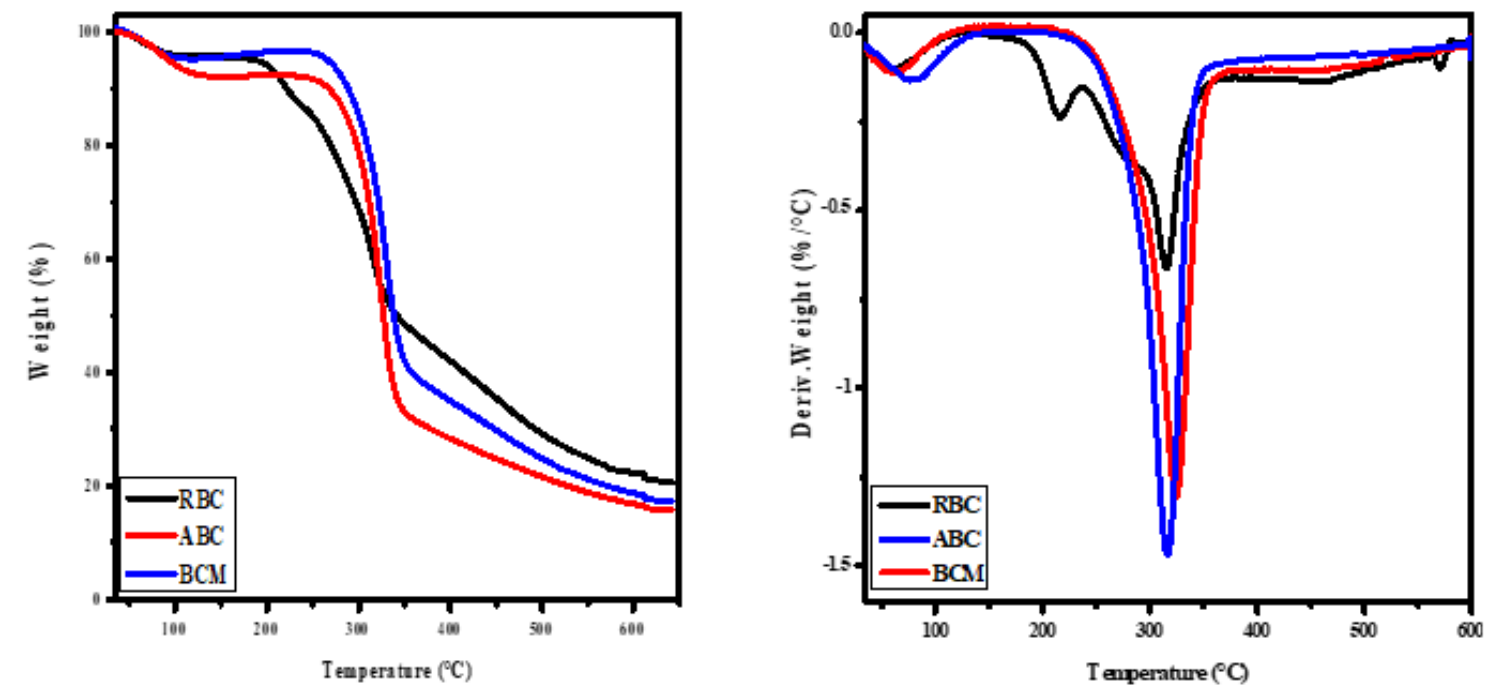

Figure 6

TGA and DTG curves of RBC, $A B C$ and BCM fibers. 


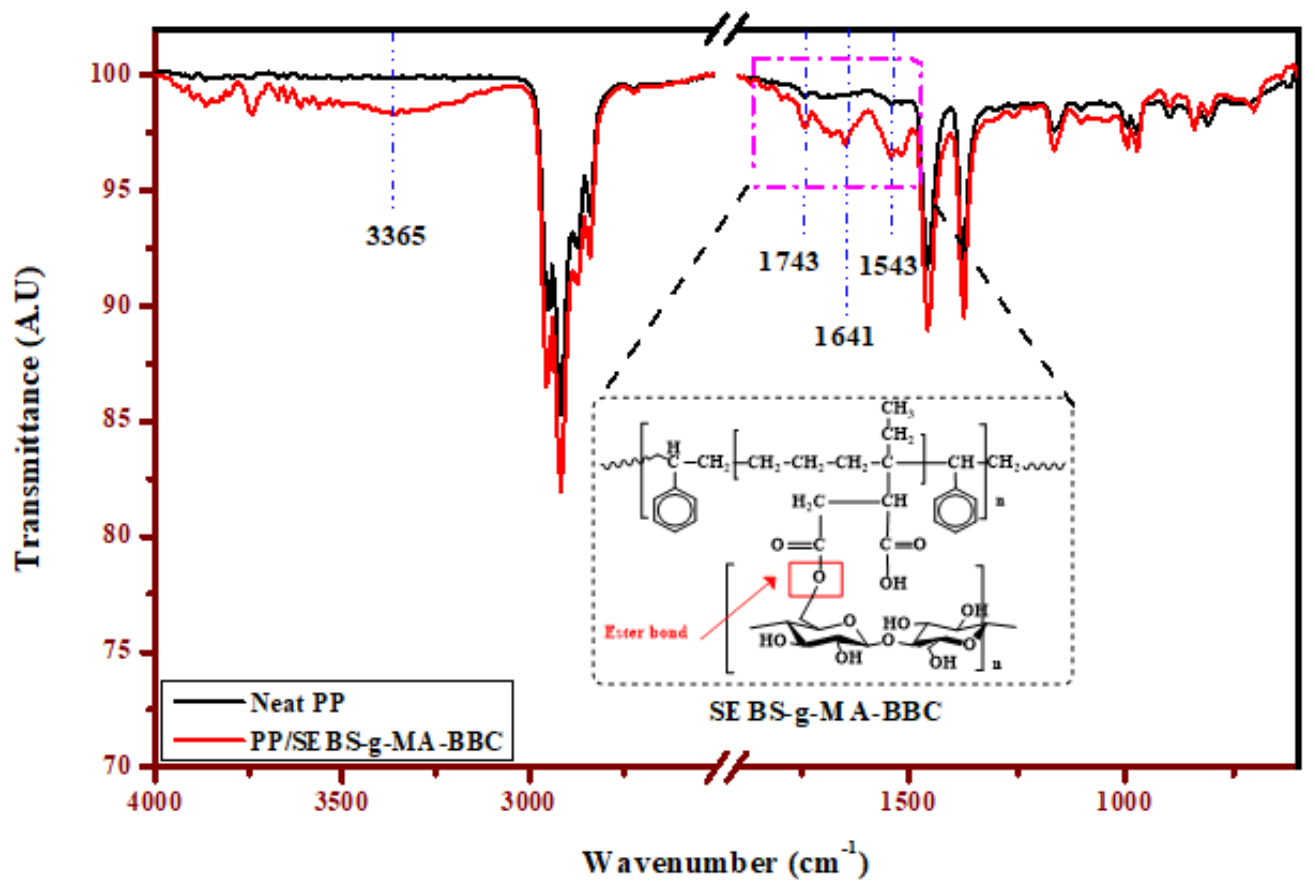

Figure 7

FT-IR spectra of neat PP and PP/SEBS-g-MA-BCM composite. 

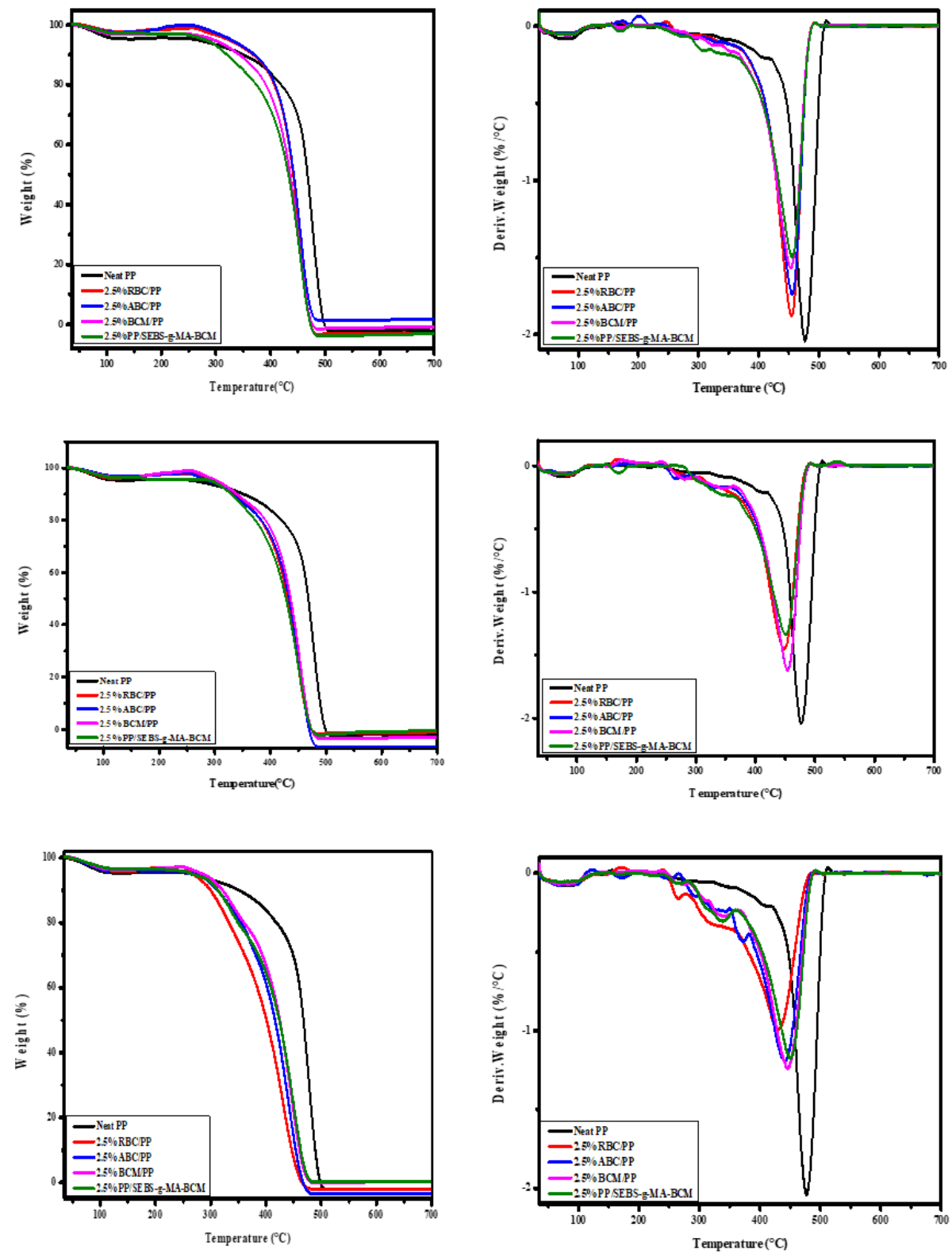

Figure 8

TGA nd DTG curves of neat PP compared to RBC/PP, ABC/ PP, BCM/ PP and PP/SEBS-g-MA-BCM composites. 


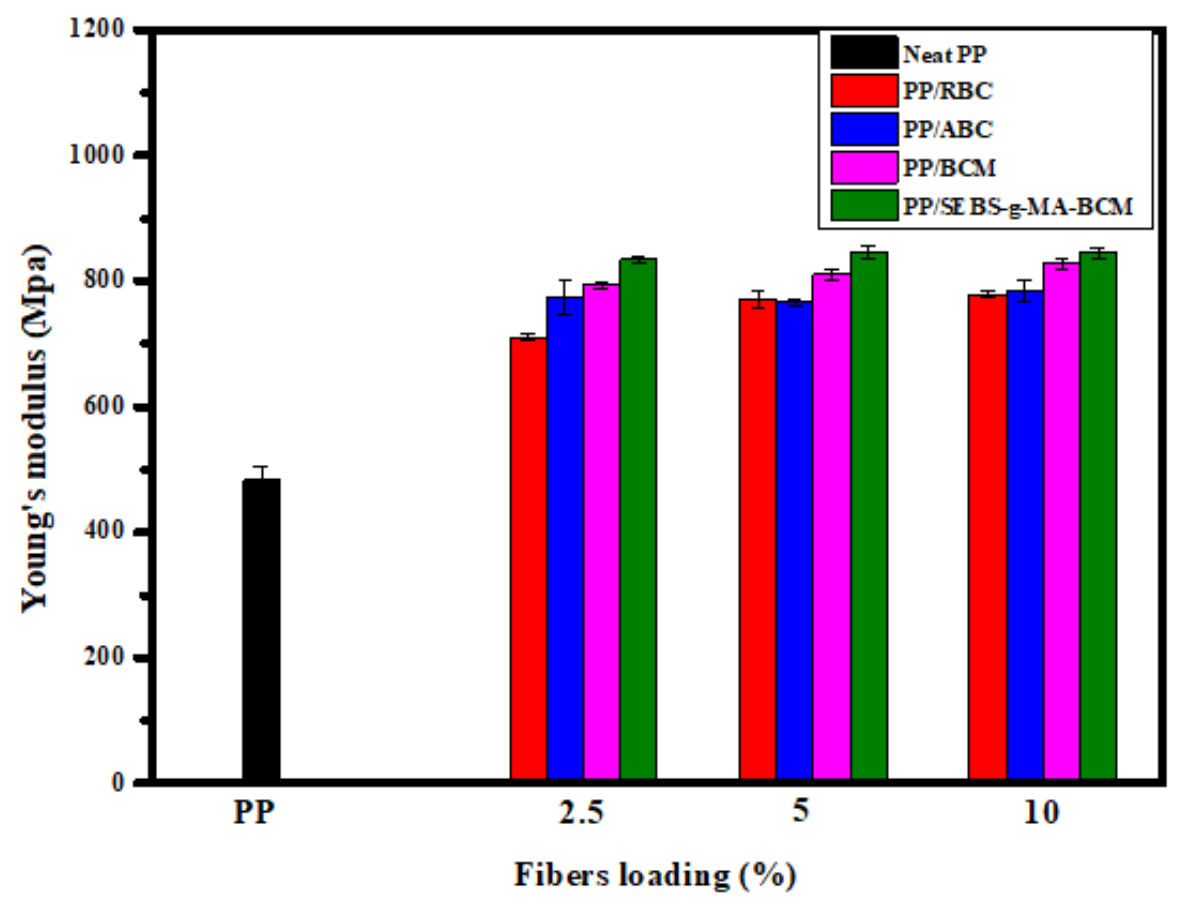

Figure 9

Young's modulus of neat PP and PP composites as function of fibers loading and chemical treatments.

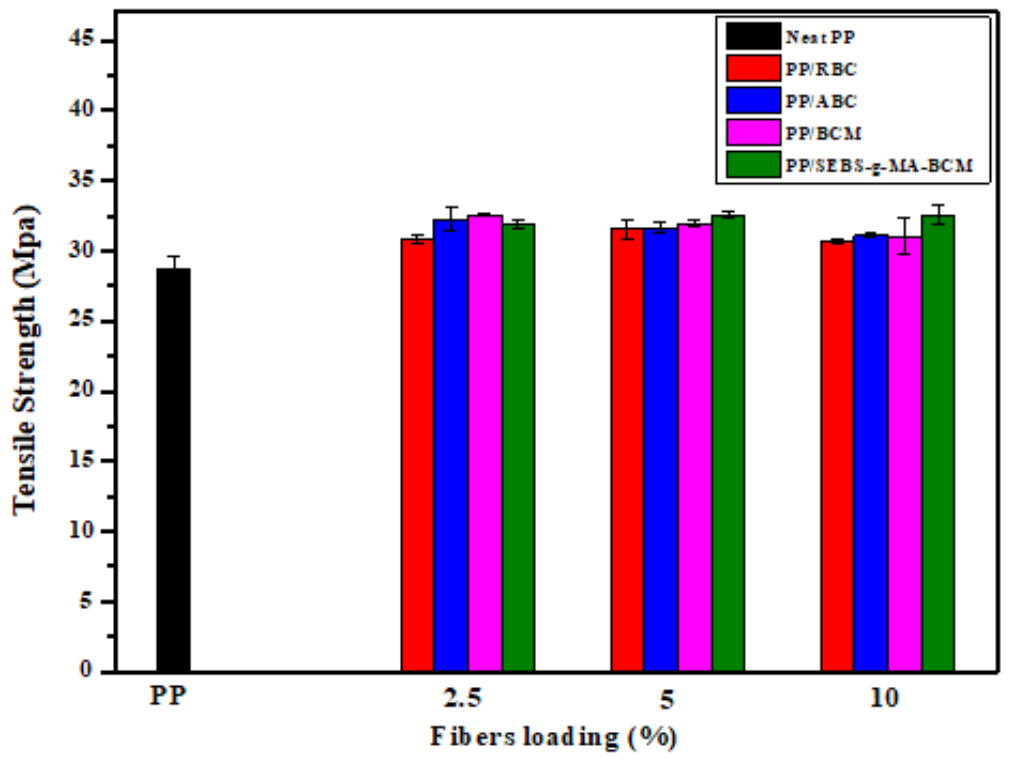

Figure 10

Tensile strength of neat PP and PP composites as function of fibers loading and chemical treatments. 


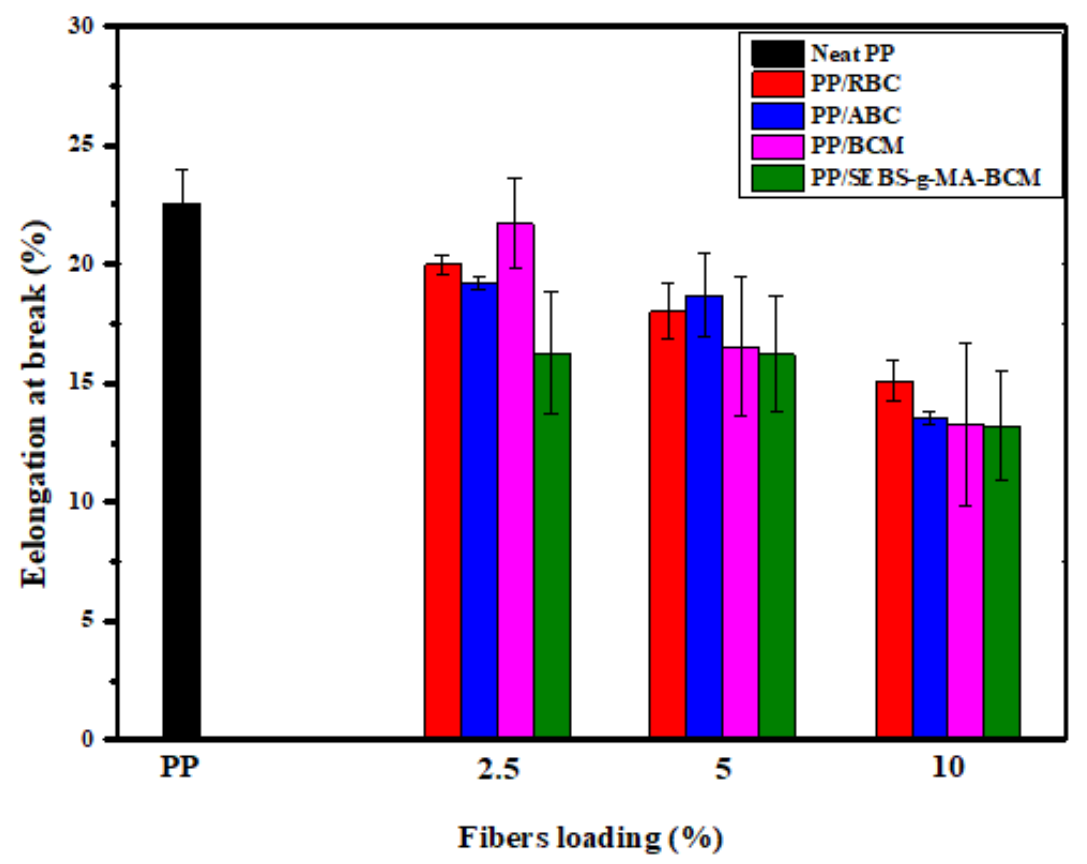

Figure 11

Elongation at break of neat PP and PP composites as function of fibers loading and chemical treatments.

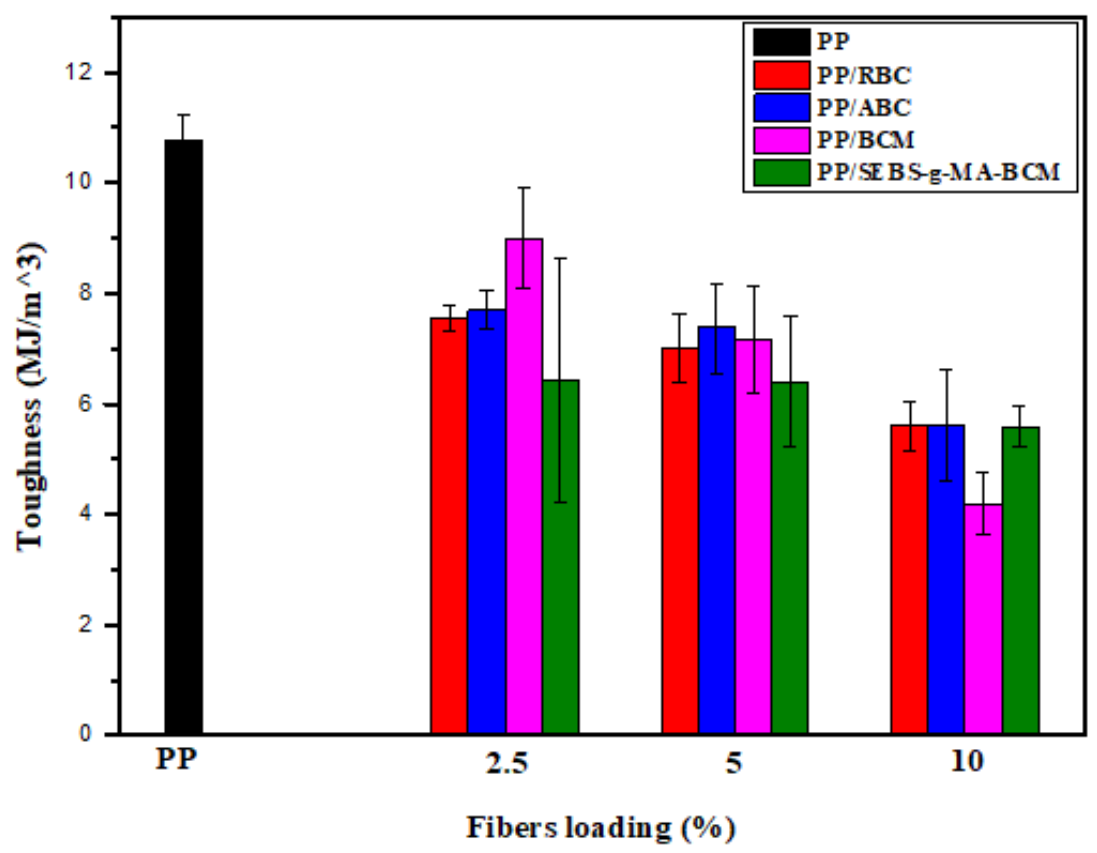

Figure 12

Toughness of neat PP and PP composites as function of fibers loading and chemical treatments. 


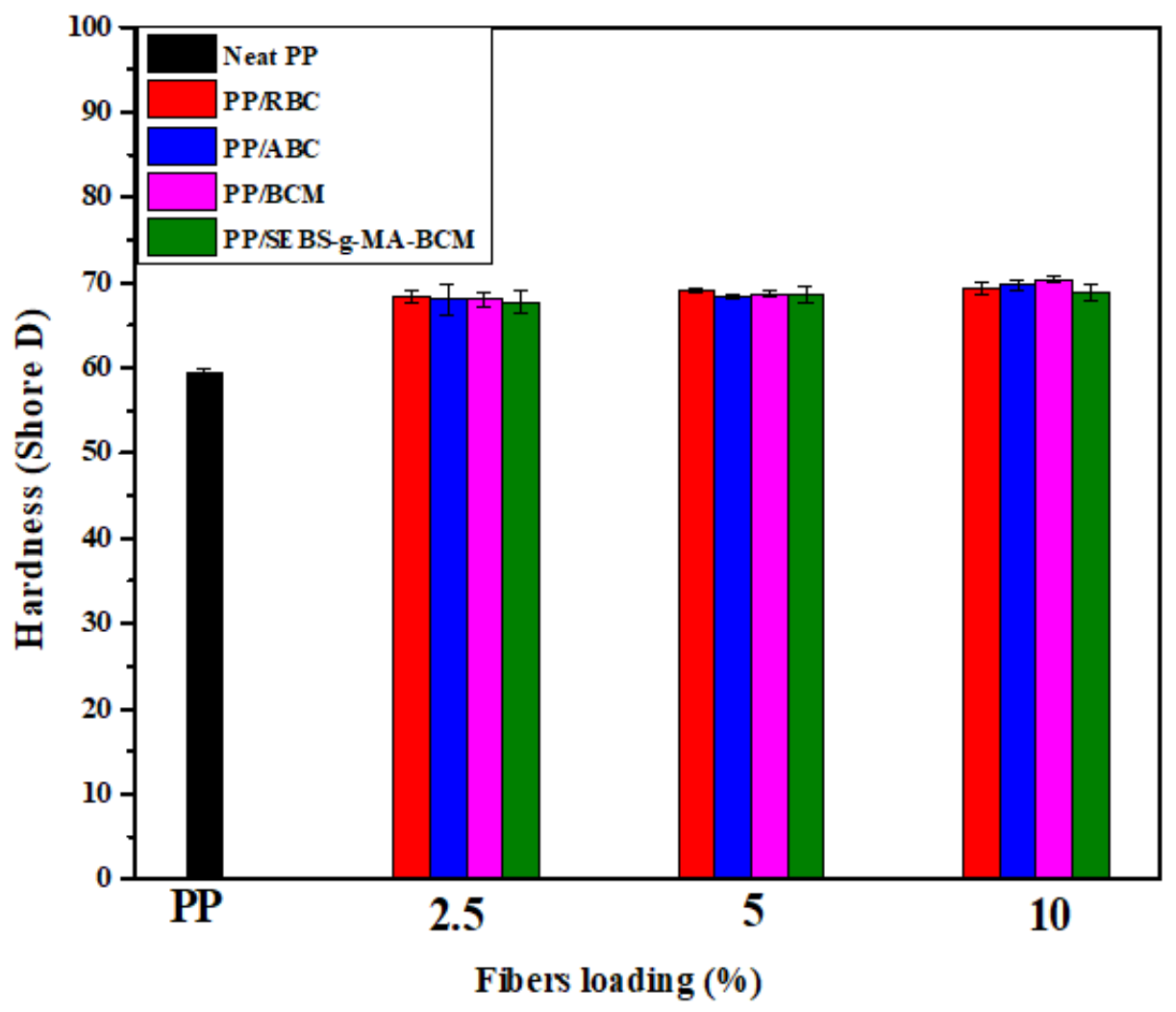

Figure 13

Hardness of neat PP and PP composites as the function of fibers loading and chemical treatments.

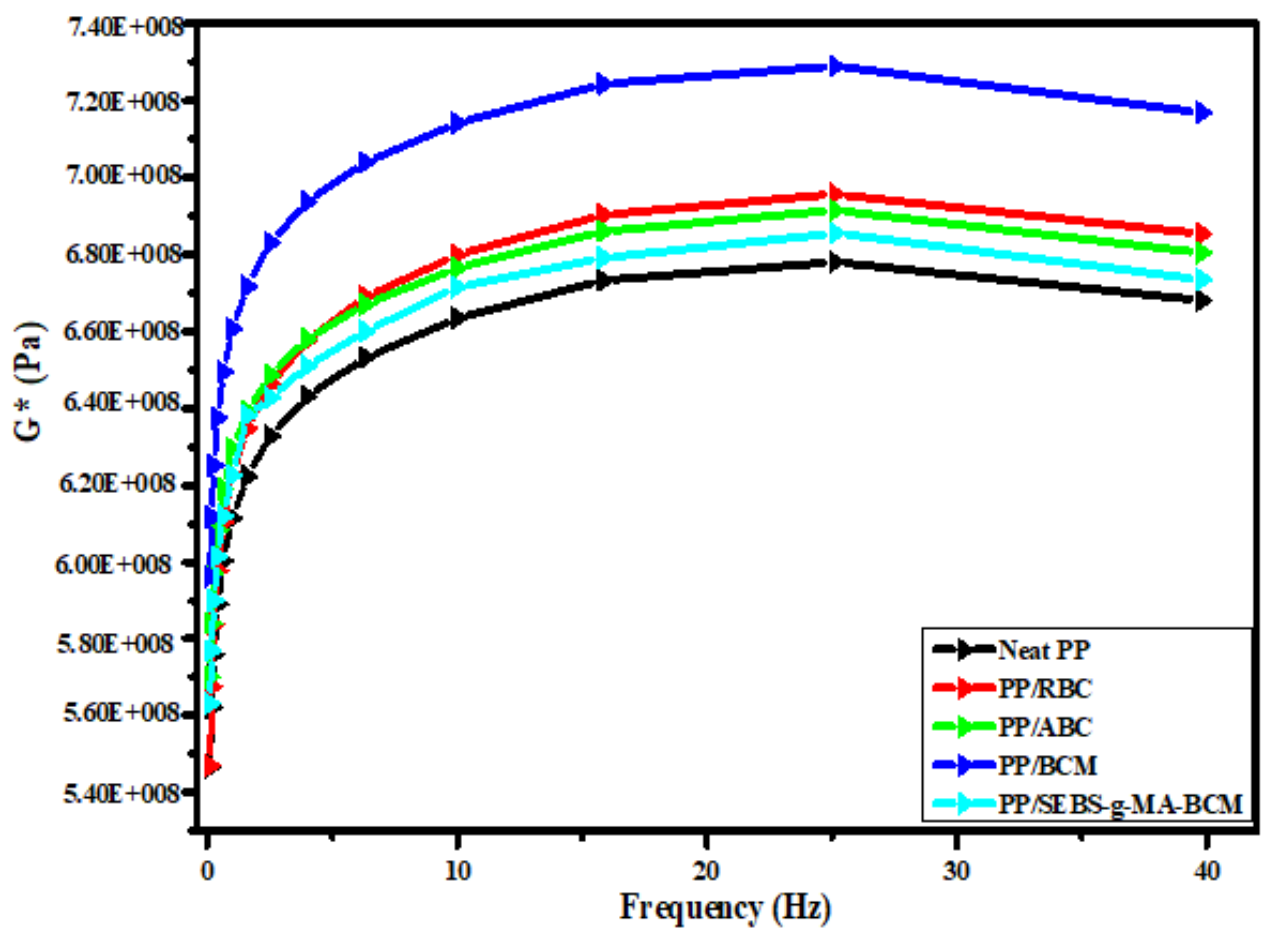

Figure 14 
The effect of dynamic sweep frequency on the variation of the complex torsion modulus( $\left.\mathrm{G}^{\star}\right)$ of PP composites reinforced with different chemically treated fibers at $10 \mathrm{wt} \%$.
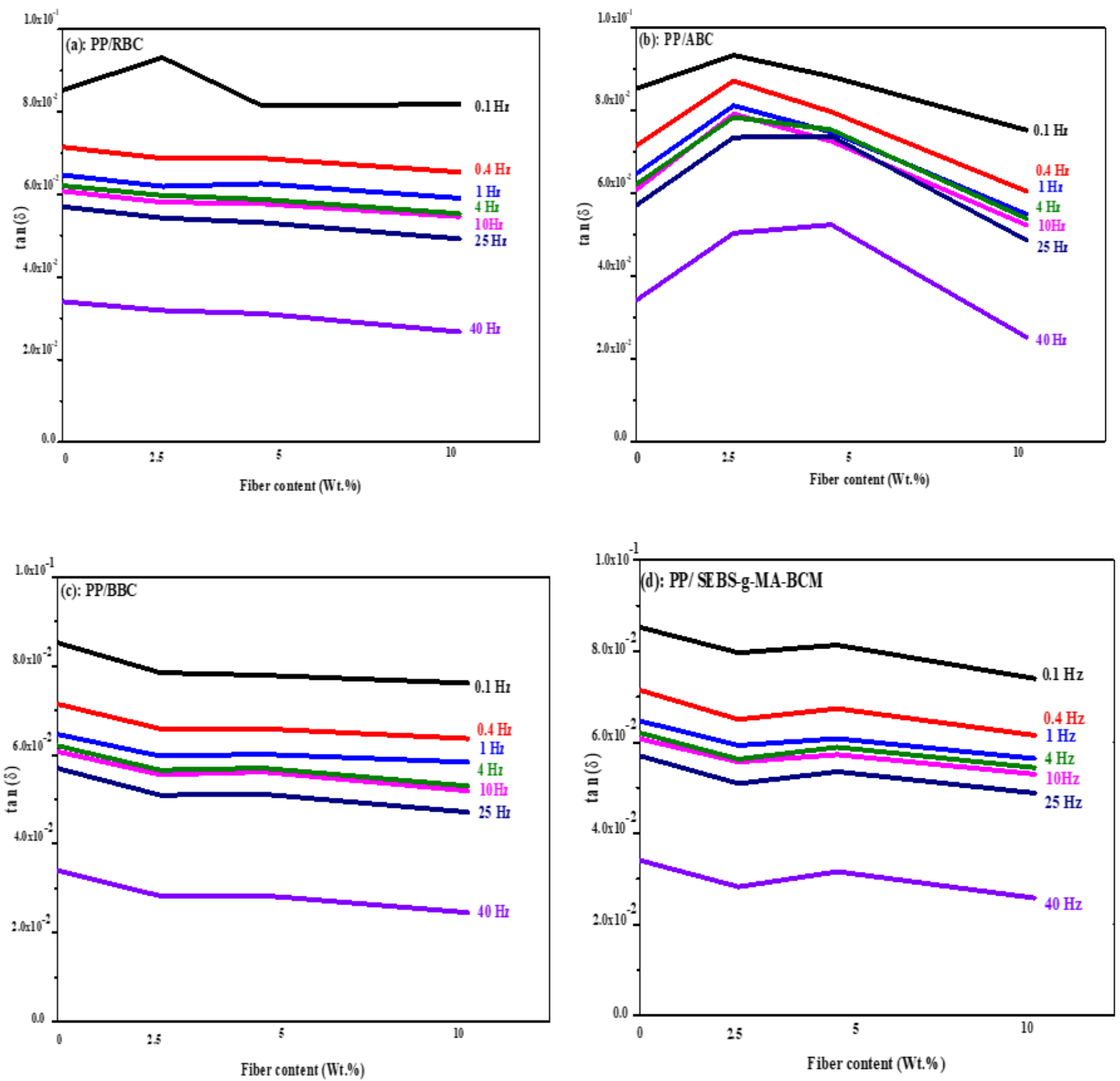

Figure 15

The effect of frequencies and fibers loading on loss modulus factor tan( $\delta)$ for different PP composites.

\section{Supplementary Files}

This is a list of supplementary files associated with this preprint. Click to download.

- GraphicalAbstract.png 